\title{
Striking reduction of amyloid plaque burden in an Alzheimer's mouse model after chronic administration of carmustine
}

Crystal D Hayes ${ }^{1 \dagger}$, Debleena Dey ${ }^{1 \dagger}$, Juan Pablo Palavicini ${ }^{1}$, Hongjie Wang $^{1}$, Kshitij A Patkar ${ }^{2}$, Dimitriy Minond ${ }^{3}$, Adel Nefzi ${ }^{2}$ and Madepalli K Lakshmana ${ }^{1 *}$

\begin{abstract}
Background: Currently available therapies for Alzheimer's disease (AD) do not treat the underlying cause of AD. Anecdotal observations in nursing homes from multiple studies strongly suggest an inverse relationship between cancer and AD. Therefore, we reasoned that oncology drugs may be effective against AD.

Methods: We screened a library of all the FDA-approved oncology drugs and identified bis-chloroethylnitrosourea (BCNU or carmustine) as an effective amyloid beta (A $\beta$ ) reducing compound. To quantify A $\beta$ levels, Chinese hamster ovary $(\mathrm{CHO})$ cells stably expressing amyloid precursor protein 751WT (APP751WT) called 7WD10 cells were exposed to different concentrations of BCNU for 48 hours and the conditioned media were collected. To detect A $\beta$ the conditioned media were immunoprecipitated with Ab9 antibody and subjected to immunoblot detection. Amyloid plaques were quantified in the brains of a mouse model of AD after chronic exposure to BCNU by thoflavin S staining.
\end{abstract}

Results: $\mathrm{BCNU}$ decreased normalized levels of $\mathrm{A} \beta$ starting from $5 \mu \mathrm{M}$ by $39 \%(P<0.05), 10 \mu \mathrm{M}$ by $51 \%(P<0.01)$ and $20 \mu \mathrm{M}$ by $63 \%(P<0.01)$ in $\mathrm{CHO}$ cells compared to a control group treated with butyl amine, a structural derivative of BCNU. Interestingly, soluble amyloid precursor protein $\alpha$ (SAPP $\alpha)$ levels were increased to $167 \%(P<$ $0.01)$ at $0.5 \mu \mathrm{M}, 186 \%(P<0.05)$ at $1 \mu \mathrm{M}, 204 \%(P<0.01)$ at $5 \mu \mathrm{M}$ and $152 \%(P<0.05)$ at $10 \mu \mathrm{M}$ compared to untreated cells. We also tested the effects of 12 structural derivatives of BCNU on $A \beta$ levels, but none of them were as potent as BCNU. BCNU treatment at $5 \mu \mathrm{M}$ led to an accumulation of immature APP at the cell surface resulting in an increased ratio of surface to total APP by $184 \%$ for immature APP, but no change in mature APP. It is also remarkable that $B C N U$ reduced $A \beta$ generation independent of secretases which were not altered up to 40 $\mu \mathrm{M}$. Interestingly, levels of transforming growth factor beta (TGF $\beta$ ) were increased at $5 \mu \mathrm{M}(43 \%, P<0.05), 10 \mu \mathrm{M}$ $(73 \%, P<0.01)$ and $20 \mu \mathrm{M}(92 \%, P<0.001)$. Most significantly, cell culture results were confirmed in vivo after chronic administration of $\mathrm{BCNU}$ at $0.5 \mathrm{mg} / \mathrm{kg}$ which led to the reduction of $\mathrm{A} \beta 40$ by $75 \%$ and amyloid plaque burden by $81 \%$. Conversely, the levels of sAPP $\alpha$ were increased by $45 \%$.

Conclusions: $B C N U$ reduces $A \beta$ generation and plaque burden at non-toxic concentrations possibly through altered intracellular trafficking and processing of APP. Taken together these data provided unequivocal evidence that $B C N U$ is a potent secretase-sparing anti-A $\beta$ drug.

See related commentary article here http://www.biomedcentral.com/1741-7015/11/82

Keywords: amyloid- $\beta$, amyloid plaques, carmustine, 1, 3 bis (2-chloroethyl)-1-nitrosourea, cytotoxicity, MTT assay, $\mathrm{LDH}$ release

\footnotetext{
* Correspondence: mlakshmana@tpims.org

+ Contributed equally

'Section of Neurobiology, Torrey Pines Institute for Molecular Studies, SW

Village Parkway 11350, Port Saint Lucie, FL 34987, USA

Full list of author information is available at the end of the article
} 


\section{Background}

Alzheimer's disease (AD) is a devastating neurodegenerative disorder of older persons presented with progressive intellectual deterioration involving memory, language, judgment and problem solving ultimately leading to a total dependence on nursing care. Recent statistics suggest that nearly 35.6 million patients are affected by AD worldwide and that about 4.6 million new cases are added each year causing an enormous social and economic burden [1]. While death rates due to stroke, heart disease and cancer have a decreasing trend, deaths related to $\mathrm{AD}$ have actually increased by $66 \%$ between 2000 and 2008 [2]. AD is responsible for causing more than 100,000 deaths each year with a total annual cost of care and treatment exceeding $\$ 100$ billion in the United States alone [2,3]. Accumulation of amyloid plaques composed of amyloid $\beta$ peptide $(A \beta)$, derived from amyloid precursor protein (APP) by consecutive actions of $\beta$ - and $\gamma$-secretases is a major hallmark of AD. Although the causal relationship between $\mathrm{A} \beta$ and $\mathrm{AD}$ is not firmly established, increasing genetic, biochemical and pathological evidence strongly implies that $A \beta$ has an early and crucial role in AD pathogenesis [4]. Therefore, most research efforts are now focused on reducing the levels of $A \beta$. More specifically, the biogenesis of $A \beta$ has been the prime validated drug target for $\mathrm{AD}$. With the failure of anti-amyloid therapy to improve cognitive measures in clinical trials including the most recent (semagacestat [5,6], homotaurine [7] tarenfurbil [8] and bapineuzumab [9]), the so called amyloid 'naysayers' are vocally suggesting that anti-amyloid therapeutic approaches be abandoned. However, improved cognitive measures that correlate well with decreased $A \beta$ levels, even up to 4.5 years after the initial vaccination with $A \beta$ in clinical trials $[10,11]$, strongly support $A \beta$ 's causal role in $A D$ and clearly suggest that reducing $A \beta$ levels in the brains of $\mathrm{AD}$ patients is an effective approach for successful therapy. Moreover, accelerated cortical atrophy continues to be well correlated with high $\mathrm{A} \beta$ deposition in multiple studies which used the most advanced technology and tracing compounds, further strengthening the pivotal role of $\mathrm{A} \beta$ in $\mathrm{AD}[12,13]$.

At present, the number of therapeutic options for $\mathrm{AD}$ remains severely limited. Currently, there are five US Food and Drug Administration (FDA)-approved drugs available for the treatment of $\mathrm{AD}$ which target either increasing cholinergic transmission or reducing glutamatergic transmission. None of them can stop or even slow down the underlying neurodegenerative process because there is an extensive multifocal neurodegeneration occurring due to accumulation of $\mathrm{A} \beta$. These drugs do not alter this underlying cause. So far, nearly 1,000 clinical trials have been attempted throughout the world to validate an effective therapy for $\mathrm{AD}$ based on all possible mechanisms of action including, in the most recent years, both $\beta$ - and $\gamma$-secretase inhibitors [14]. The classes of drugs being investigated include growth factors, $\mathrm{Ca} 2+$ antagonists, intravenous immunoglobulin, alpha secretase stimulators, $A \beta$ oligomer inhibitors, metal chelators, neuroprotective agents, cholesterol lowering drugs, anti-inflammatory agents, anti-epileptics and immunization [15]. Unfortunately, instead of improving their cognitive measures, many patients experienced worsening of the symptoms and some patients even developed skin cancer after treatment with semagacestat, a $\gamma$-secretase inhibitor $[5,6]$. The most likely explanation for the failure of $\gamma$-secretase inhibitors in the clinical trials is because $\gamma$-secretase has dozens of target proteins particularly notch signaling which is crucial for cell-cell communication, immune system formation and cell proliferation and survival [16]. For $\beta$-secretase (BACE), in addition to having dozens of other substrates, the active site is so large that only compounds with more than 500 molecular weight may efficiently inhibit the enzyme, but then they are unable to pass through the blood-brain barrier (BBB) [17]. More importantly, multiple labs have reported that BACE1 deficiency in genetically engineered mice is associated with impaired learning [18], further defeating the very purpose for which it is intended. Although effective BACE inhibitors have been shown in recent years to lower A $\beta$ levels in animal models $[19,20]$, overall, secretase inhibitors have so far failed to demonstrate the expected efficacy against $\mathrm{AD}[6]$. Therefore, alternative targets that may modulate $A \beta$ generation, preferably without directly inhibiting $\gamma$-secretase or BACE, are very important at this juncture.

Significantly, $A \beta$ has been implicated to play a vital role in the pathogenesis of not only AD but also traumatic brain injury (TBI) [21], cerebral amyloid angiopathy (CAA) [22], glaucoma [23] and Niemann-Pick type $C$ disease [24]. As with $A D$, there are no effective prevention or treatment strategies for these disorders. Therefore, development of any safe secretase-sparing anti-A $\beta$ drug would have wider clinical applications.

It is also important to note that there is a strong relationship between cancer and AD. For instance, a recent population based cohort study revealed a $43 \%$ lower risk of ever developing AD among cancer patients [25]. Similarly, patients diagnosed with $\mathrm{AD}$ showed a 69\% lower risk of developing cancer [25]. These observations have been confirmed by longitudinal prospective studies [26]. Because of the solid relationship between AD and cancer, we speculated that anticancer drugs may exert favorable effects on AD. Therefore, we decided to screen all FDAapproved oncology drugs in a cell-based assay and identified bis-chloroethylnitrosourea (BCNU or carmustine) as a potential anti-A $\beta$ drug.

Here we show for the first time that BCNU-exposed Chinese hamster ovary $(\mathrm{CHO})$ cells have significantly 
reduced levels of amyloid $\beta$ peptide (A $\beta$ ) and c-terminal fragments (CTFs) in cell cultures. Also, chronic administration of $\mathrm{BCNU}$ for 60 days in a mouse model of $\mathrm{AD}$ robustly decreased levels of $A \beta 40$ and amyloid plaque burden at six months of age. More importantly, $A \beta$ levels and plaque burden were reduced at non-toxic concentrations of $\mathrm{BCNU}$ independent of secretases suggesting that $\mathrm{BCNU}$ may be an effective $\mathrm{A} \beta$ lowering, disease-modifying drug against $\mathrm{AD}$.

\section{Methods}

\section{Chemicals and antibodies}

The FDA-approved oncology drug set II was obtained from the open chemical repository of the National Cancer Institute/National Institutes of Health Developmental Therapeutics Program (NCI/NIH DTP) [27]. 1, 3 bis (2chloroethyl)-1-nitrosourea (BCNU) or carmustine (cat\# C0400), thioflavin S (cat \#T1892), ethylene glycol tetraacetic acid (EGTA) (cat \# E4378), paraformaldehyde (PFA) (cat \# P6148), dimethyl sulfoxide (DMSO) (cat \# 472301) and glutaraldehyde (cat \# G-7776) were all purchased from Sigma-Aldrich (St. Louis, MO, USA). EZ-Link SulfoNHS-LC-biotin was from Pierce (Rockford, IL, USA). The monoclonal antibody Ab9 used for immunoprecipitation of $A \beta$ was purified from supernatants of the hybridoma generated in mice by Biomatik Corporation (Ontario, ON, Canada). The polyclonal antibody CT15 (against C-terminal 15 residues of APP) and the polyclonal antibody, 63G (against mid region of APP) have been described previously $[28,29]$. The monoclonal antibody $6 \mathrm{E} 10$ (cat \# SIG39300, recognizing 1- 17 of $A \beta$ sequence) was obtained from Covance Research (Denver, CO, USA). Polyclonal anti-sAPP $\beta$-WT antibody (cat \# 18957) was purchased from IBL Co. Ltd (Gunma, Japan). Monoclonal anti-Iba1AIF1 antibody (cat \# MABN92) was purchased from Millipore (Billerica, MA, USA). Polyclonal anti-TGF beta 1 antibody (cat \# NBP1-67698) was purchased from Novus Biologicals (Littleton, CO, USA). Mouse monoclonal antibody against beta-actin (cat \# A00702) was purchased from Genscript USA Inc. (Piscataway, NJ, USA). Secondary antibodies, such as peroxidase-conjugated AffiniPure goat anti-mouse (Code \# 115-035-146) and ant-rabbit (code \# 111-035-144) immunoglobulin Gs (IgGs), were purchased from Jackson ImmunoResearch Laboratories (West Grove, PA, USA). Anti-mouse IgG and anti-rabbit IgG-agarose beads were from American Qualex International (San Clemente, CA, USA). ADAM10 and 17 enzymes, and the substrate for inhibition assays were purchased from R\&D Systems (Minneapolis, MN, USA; cat\#: 936-AD-020, 930-ADB-010, ES010, respectively).

\section{Quantitation of $A \beta$, CTFs and sAPPs in 7WD10 cells}

The methods for the generation and characterization of CHO cells stably expressing APP751wt (7WD10 cells) for the secretion of $A \beta$ into the conditioned medium (CM) have been described previously $[28,29]$. To immunoprecipitate $\mathrm{A} \beta, 7 \mathrm{WD} 10$ cells were grown in six-well plates and were treated with $\mathrm{BCNU}$ at final concentrations of $0,0.5,1.0,5.0,10.0$ and $20.0 \mu \mathrm{M}$ in duplicate wells. After 48 hours, the CM was collected, centrifuged to remove cell debris and immunoprecipitated overnight using a monoclonal Ab9 antibody (recognizes $1-16$ amino acids of $A \beta$ ) to pull-down total $A \beta$. After SDSPAGE electrophoresis using NuPAGE $4 \%$ to $12 \%$ bis-tris gels, total $A \beta$ was detected by immunoblotting using a mixture of $6 \mathrm{E} 10 / 82 \mathrm{E} 1$ antibodies which reliably detects total $A \beta$ as described previously $[28,29]$. The $C M$ was also immunoblotted to detect SAPP $\alpha$ (6E10), sAPP $\beta$ (anti-sAPP $\beta$-wt rabbit IgG from IBL America Ltd) and sAPPtotal (63G) using the indicated antibodies. To detect APP holoprotein and CTFs (CT15 antibody raised against the last 15 amino acids of APP), the cells were lysed using lysis buffer ( $1 \%$ Nonidet P-40) with complete protease inhibitor mix (Sigma) and equal amounts of proteins were loaded into each well and subjected to SDS-PAGE electrophoresis. Following transfer onto polyvinylidene difluoride (PVDF) membranes, they were blocked with 5\% milk in Tris-buffered saline with Tween (TBS-T) and incubated overnight with primary antibodies followed by one to four hours of incubation with horseradish peroxidase (HRP)-conjugated secondary antibodies, such as monoclonal mouse anti-goat IgG light chain or monoclonal mouse anti-rabbit IgG light chain. The protein signals were detected using Super Signal West Pico Chemiluminescent substrate (Pierce). Quantitation of Western blot signals was done using Java-based ImageJ software available freely from NIH.

\section{APP turn-over and surface biotinylation experiments}

Near confluent 7WD10 cells in duplicate wells were treated with BCNU at $10.0 \mathrm{mM}$ concentration and after 24 hours, washed two times with cold PBS and incubated with $2.0 \mathrm{mg} / \mathrm{ml}$ sulfo-NHS-LC-biotin in PBS, $\mathrm{pH} 8.0$ under ultra-low shaking on ice in the cold room. After an hour of incubation, cells were washed three times in PBS and lysates were prepared using 1\% Nonidet P-40 lysis buffer containing complete protease mix as described above. Biotinylated proteins were pulled-down by immunoprecipitation with anti-biotin antibody plus antimouse agarose beads. The samples were subjected to SDS-PAGE and APP was detected with CT15 antibody. To assess the effect of BCNU on APP stability, cycloheximide experiments were done essentially as previously described in our published papers [28,29]. Briefly, $7 \mathrm{WD} 10$ cells were incubated with cycloheximide at a concentration of $100 \mathrm{mg} / \mathrm{ml}$ in $\mathrm{PBS}$ at $37^{\circ} \mathrm{C}$ in a $\mathrm{CO}_{2}$ incubator. Treated and untreated cells were harvested and lysed at $0,15,30,60$, and 120 minutes. The lysates 
were processed to detect APP with CT15 antibody as described above.

\section{Measurement of activities of secretase enzymes}

Enzyme activities were measured using partially purified enzymes from mouse brain homogenates using commercially available kits for BACE (cat \# 565785, EMD Millipore, a division of Merck KGaA, Darmstadt, Germany) and $\gamma$-secretase (cat \# FP003, R\&D Systems) according to the manufacturer's instructions. The fluorogenic substrate used for BACE was glu-val-lys-met-asp-ala-glu-phe-lys, and for $\gamma$-secretase was NMA-GGVVIATVK (DNP)DRDRDR-NH2. The procedure briefly includes membrane isolations from the mouse brains at $4{ }^{\circ} \mathrm{C}$ by homogenization using an extraction buffer (20 mM HEPES, $\mathrm{pH} 7.5 ; 50$ $\mathrm{mM} \mathrm{KCl}$ and $2 \mathrm{mM}$ EGTA). Lysates were centrifuged at $800 \mathrm{~g}$ for 10 minutes to remove nuclei and large cell debris in the pellet and the supernatants collected. The pellets were re-homogenized and more supernatants were collected in the same way. The resulting supernatants were pooled and centrifuged at 100,000 g for 1 hour at $4{ }^{\circ} \mathrm{C}$. The resulting membrane pellet was washed once in extraction buffer and suspended in the same buffer plus $10 \%$ glycerol and flash-frozen in liquid nitrogen and stored at $-80^{\circ} \mathrm{C}$ until used. The total protein concentrations in membrane preparations were determined using the $\mathrm{BCA}$ method (Pierce). Membranes were resuspended at $0.5 \mathrm{mg} / \mathrm{ml} \mathrm{con-}$ centrations in resuspension buffer and solubilized at $4^{\circ} \mathrm{C}$ for one hour with end-over-end rotation. Following centrifugation at 100,000 $\mathrm{g}$ for one hour, the supernatants were collected.

The assay mixture consisted of $50 \mathrm{ul}$ of partially purified enzyme preparation, $48 \mathrm{ul}$ of 2 times reaction buffer (20 mM HEPES, pH, 7.0; $150 \mathrm{mM}$ of $\mathrm{KCl} ; 2 \mathrm{mM}$ EGTA; $1 \%(\mathrm{~W} / \mathrm{V}) \mathrm{CHAPSO}$ ) and $2 \mathrm{ul}$ of BACE or $\gamma$-secretase substrate. The mixture was incubated for two hours in the dark and fluorescence was read at $320 / 420 \mathrm{~nm}$ for BACE and $355 / 440 \mathrm{~nm}$ for $\gamma$-secretase. Some samples also included BACE or $\gamma$-secretase specific inhibitors to confirm the specificity of enzyme activity. One negative control without lysate and another without substrate were included. The positive control included was $2.0 \mathrm{ul}$ of recombinant BACE enzyme. The enzyme activity was calculated per mg protein and was expressed as percentage change in BCNU-treated samples from untreated controls.

ADAM10 and 17 inhibition assays followed the same general protocol: $5 \mu \mathrm{L}$ of $3 \mathrm{x}$ enzyme solution (3 and $30 \mathrm{nM})$ in assay buffer (10 mM HEPES, $0.001 \%$ Brij-35, pH 7.5 ) were added to solid bottom white 384 low volume plates (Nunc cat\# 264706). Next, $5 \mu \mathrm{L}$ of test compounds or pharmacological controls were added to corresponding wells. After 30 minutes incubation at room temperature (RT) the reactions were started by addition of $5 \mu \mathrm{L}$ of $3 \mathrm{x}$ solutions of substrate $(30 \mu \mathrm{M})$. Fluorescence was measured every 30 minutes for 2 hours using the multimode microplate reader Synergy H4 (Biotek Instruments, Winooski, VT, USA) using $\lambda_{\text {excitation }}=324 \mathrm{~nm}$ and $\lambda_{\text {emission }}=405 \mathrm{~nm}$. Rates of hydrolysis were obtained from plots of fluorescence versus time, and inhibition was calculated using rates obtained from wells containing substrate only (100\% inhibition) and substrate with enzyme ( $0 \%$ inhibition). The $\mathrm{IC}_{50}$ value of the pharmacological control ((N-hydroxy-1-(4methoxyphenyl)sulfonyl-4-(4-biphenylcarbonyl)piperazine2-carboxamide, Calbiochem cat\#: 444252) was also calculated to ascertain the assay robustness.

\section{Cytotoxicity assays}

As oncology drugs are generally cytotoxic, we wanted to identify the minimal concentrations of BCNU necessary for cytotoxicity. Neuro-2A (N2a) cells were incubated with $\mathrm{BCNU}$ at final concentrations of $0,0.1,1.0,5.0,10.0,20.0$, 80.0 and $240.0 \mathrm{uM}$ for 24 hours. To determine cell viability, first we used the calorimetric 3-(4,5-dimethylthiazol2-yl)-2,5-diphenyltetrazolium bromide (MTT) metabolic activity assay using a cell growth determination kit (cat \# CGD-1, Sigma Aldrich) according to the manufacturer's instructions. Briefly, the supernatant was removed, cells were washed two times with PBS and $20 \mu \mathrm{l}$ of MTT solution $(5 \mathrm{mg} / \mathrm{ml}$ in PBS) plus $100 \mu \mathrm{l}$ of medium were added. Following four hours of incubation at $37^{\circ} \mathrm{C}$, the resulting formazan crystals were dissolved in $100 \mu \mathrm{l}$ of DMSO and the absorbance was read at $570 \mathrm{~nm}$ within an hour using the Smart Spec Plus spectrophotometer (Bio-Rad). Cells treated with medium only served as controls.

To reproduce and confirm these results, we also measured cell viability using an in vitro toxicology assay kit based on secretion of lactic dehydrogenase (LDH) (cat \# TOX7, Sigma Aldrich). The assay is based on reduction of nicotinamide adenine dinucleotide (NAD) by $\mathrm{LDH}$ enzyme into NADH which converts tetrazolium dye to a colored compound that can be quantitated spectrophotometrically. The procedure briefly is as follows: after 24 hours incubation of cells with BCNU at different concentrations, $50 \mu \mathrm{l}$ of LDH assay lysis solution was added to each well and further incubated at $37^{\circ} \mathrm{C}$ for 45 minutes. The assay mixture was freshly prepared by adding equal volumes of substrate, dye and cofactor; $50 \mu \mathrm{l}$ of LDH assay mixture was added to each of the $50 \mu \mathrm{l}$ aliquots of the test medium. The plates were sealed with aluminum foil to protect from light and incubated for 30 minutes at $37^{\circ} \mathrm{C}$. The reaction was terminated by adding $10 \mu \mathrm{l}$ of $1 \mathrm{~N} \mathrm{HCl}$ and the absorbance was measured at a wavelength of $490 \mathrm{~nm}$.

\section{Staining of amyloid plaques}

APdE9 mice that overexpress both APP with Swedish mutation and PS1 with $\triangle \mathrm{E} 9$ deletion were used as a robust mouse model of Alzheimer's disease. All animal 
procedures were carried out strictly following the National Institutes of Health's 'Guide for the Care and Use of Animals' and using the animal protocol as approved (protocol \# TPI-03-11) by the Torrey Pines Institute's Animal Care and Use Committee (IACUC). $\mathrm{BCNU}$, dissolved initially in DMSO and further diluted in saline, was administered to mice daily by intraperitoneal injections at $0.5 \mathrm{mg} / \mathrm{kg}$ body weight starting from four months of age until six months of age for 60 days. Age and genotype-matched control mice received vehicle injections for the same period of time. Following the treatment period, mice were anesthetized by isoflurane and perfused using a mixture of $4 \%$ PFA and $0.02 \%$ glutaraldehyde in PBS. After 72 hours, the brains were dehydrated using sucrose gradient. Brains were frozen in optimal cutting temperature (OCT) solution and coronal sections of $16 \mu \mathrm{M}$ thickness were cut by cryostat at $-19^{\circ} \mathrm{C}$ to $21^{\circ} \mathrm{C}$ and transferred to superfrost slides. The slides were rinsed twice with distilled water for five minutes. The slides were then immersed in $1 \%$ thioflavin $\mathrm{S}$ solution prepared in $50 \%$ ethanol for five minutes and then differentiated in $70 \%$ ethanol for five minutes, rinsed again twice in water for five minutes and coverslipped with Sure mount (EMS) mounting media and held at $4^{\circ} \mathrm{C}$ until they were imaged. Images were captured using a Zeiss Examiner D1 microscope. All images were acquired at the same exposure and were automatically aligned using the stitching tool in the Axiovision LE software. Once acquired, all images were opened in Image J and were normalized; the threshold was set for each image using the histogram mean at the same standard deviation. Each image was adjusted to the threshold and set to scale in pixels. The parameters measured include the area, integrated density, perimeter, and feret's diameter for each plaque. To help eliminate background the particle size pixel was set at 30-infinity pixel. To quantify plaques, the brain level of cut sections was fixed for all mice at the region of the motor cortex and hippocampus corresponding to the starting section at interaural $2.34 \mathrm{~mm}$ and Bregma $-1.46 \mathrm{~mm}$ of 'The Mouse Brain Atlas' by George Paxinos and Keith Franklin. A fixed thickness of $16 \mu \mathrm{M}$ coronal sections at regular intervals was maintained in all animals. The amyloid plaques were quantified from throughout the sections from five sections per mouse and mean values were generated for each mouse. Pictures were montaged and, for quantification by image J software, the color images were converted in to HSV format and 8-bit channels. Plaques were quantified in an unbiased manner by an investigator blind to the treatment nature of the samples. Plaque burden was calculated as the area occupied by the plaques divided by the total brain region area. The data are expressed as percent change in means from the controls.

\section{Quantitation of $A \beta 40$ levels in the brain by ELISA}

A $\beta 40$ levels in the brain extracts were determined by sandwich ELISA. Briefly, the wet mass of the brain was weighed and homogenized thoroughly in cold 1\% CHAPSO/PBS with protease inhibitors. The homogenate was ultra-centrifuged at 100,000 g for 60 minutes. The samples were further diluted to 40-fold and stored on ice until use. The A $\beta$ standard (Bachem) was dissolved in hexafluoroisopropanol at $1 \mathrm{mg} / \mathrm{ml}$, sonicated and dried under nitrogen. The dried A $\beta 40$ was resuspended in DMSO, separated into aliquots and frozen at $-80^{\circ} \mathrm{C}$. The rest of the protocol is exactly as described previously from our laboratory [28]. The quantity of $A \beta 40$ in each sample was measured in quadruplicate. Total protein concentrations were determined using the BCA assay (Pierce).

\section{Iba1 I mmunohistochemistry}

Brain sections (18 um) from saline- and BCNU-treated mice were washed two times with PBS $1 \mathrm{X}$ for five minutes. Antigen retrieval was carried out by immersing slides in $10 \mathrm{mM}$ citric acid ( $\mathrm{pH}$ 6.0) for 10 minutes at $90^{\circ} \mathrm{C}$. Sections were washed three times with PBS $1 \mathrm{X}$ for five minutes and incubated in blocking solution (10\% normal goat serum, $1 \%$ BSA, $0.1 \%$ Triton $\mathrm{X}-100$ in PBS $1 \mathrm{X}$ ) for one hour at RT. The sections were incubated overnight with anti-Iba1/ALF1 mouse monoclonal antibody (Millipore) in blocking solution $(1: 200)$ at $4^{\circ} \mathrm{C}$. After washing three times in PBS $1 \mathrm{X}$ for 5 minutes, the sections were incubated with Alexa Fluor ${ }^{\circledR} 568$ goat anti-mouse IgG (Invitrogen) in blocking solution (1:500) at RT for two hours in the dark. Finally, slides were washed three times with PBS for five minutes, covered with mounting medium for fluorescence with 4',6-diamidino-2-phenylindole (DAPI) (Vector Laboratories) and sealed with nail clear. Sections were visualized in a fluorescence microscope (Axio Examiner D1) and a confocal microscope (Nikon 90i, scan head-C1 SHS, Melles Griot laser system). Microglia were counted in a defined area of the motor cortex and hippocampus (CA3) using the Image-Pro Plus (Media Cybernetics) software package. Positive cells were defined as those whose nuclei and processes were evidently stained for Iba1 and whose nuclei were co-localized with DAPI.

\section{Quantitation of BCNU drug levels in the brain}

Two sets of three mice each were injected with BCNU at $4 \mathrm{mg} / \mathrm{kg}$ body weight and euthanized after either 5 or 20 minutes. The brains were rapidly removed, frozen and weighed before being homogenized in $250 \mu \mathrm{L}$ of Dulbecco's PBS (dPBS), immediately followed by $750 \mu \mathrm{L}$ of acetonitrile. The samples were spun for 10 minutes at $10,000 \mathrm{rpm}$ at $4^{\circ} \mathrm{C}$. The supernatant was removed and the samples were dried for two hours. The pellets were left at $4^{\circ} \mathrm{C}$ overnight, and on the following day samples 
were reconstituted in $30 \%$ acetonitrile, vortexed, and spun at $13,000 \mathrm{rpm}$ for five minutes at $4^{\circ} \mathrm{C}$. To assess stability of BCNU in the blood, blood samples were collected from several mice after anesthesia with isoflurane and $200 \mu \mathrm{L}$ of blood was mixed with $8 \mu \mathrm{L}$ of EDTA (final concentration $1.5 \mathrm{mg} / \mathrm{mL}$ ) and about $100 \mu \mathrm{g}$ of BCNU in $4 \mu \mathrm{l}$. The mixture was allowed to stand in a $37^{\circ} \mathrm{C}$ water bath for 0, 5, 10, 15 and 30 minutes. After the chase time, $600 \mu \mathrm{L}$ of $100 \%$ acetonitrile was added to the sample. The samples were spun at 3,000 g for five minutes and the supernatant was collected. Each sample was made in triplicate, with the exception of the 0 minute blood which was done in duplicate. The blood samples were dried for approximately three hours. The pellet was reconstituted using $100 \mu \mathrm{L}$ of $30 \%$ acetonitrile, vortexed and spun at 13,000 $\mathrm{g}$ for five minutes. The samples were transferred to shelf pack vials and run on the UV mass spectrometer. Similarly, to assess BCNU stability in the brain homogenates, three mice were anesthetized with isoflurane, perfused with $\mathrm{dPBS}$ and their brains collected. Brains were homogenized in $250 \mu \mathrm{L}$ of dPBS and $200 \mu \mathrm{L}$ of brain homogenate was incubated with $100 \mu \mathrm{g}$ of $\mathrm{BCNU}$ for 1,15 , or 30 minutes at $37^{\circ} \mathrm{C}$. After the chase time, $750 \mu \mathrm{L}$ of $100 \%$ acetonitrile was added to the sample. The rest of the procedure was similar to the samples prepared for blood. All analyses were performed in triplicate.

The samples were then run on the UV mass spectrometer. The liquid chromatography system (Shimadzu, Kyoto, Japan) consisted of a LC20AD binary solvent delivery pump, a DGU-20A 5 degasser, CTO-20A column oven and a SPD-M20A photodiode array detector. Chromatographic separation was carried out on a $\mathrm{C}-18$ reverse phase column (Luna $50 \mu, 100 \AA, 50 \times 4.6 \mathrm{~mm}$ ) fitted with a $\mathrm{C}-18$ reverse phase guard cartridge (Phenomenex, $4 \times$ $3.00 \mathrm{~mm}$ ) and BCNU was eluted using a gradient of solvents $A(0.1 \%$ formic acid in water $)$ and $B(0.1 \%$ formic acid in acetonitrile) at $0.5 \mathrm{~mL} / \mathrm{minute}$ flow rate. The gradient was $5 \%$ to $65 \%$ B over 20 minutes, $65 \%$ to $95 \%$ B over one minute, and kept for two minutes and restored to $5 \%$ $\mathrm{B}$ in one minute followed by re-equilibration for five minutes. The peak for BCNU was monitored at $280 \mathrm{~nm}$ by injecting $5 \mu \mathrm{L}$ of the sample.

\section{Statistical analysis}

The signal intensities of immunoblots of the samples treated with $\mathrm{BCNU}$ in $\mathrm{CHO}$ cells as well as plaque burden in the mouse brain were quantified using publicly available Java-based Image J software developed at the National Institutes of Health. All data were analyzed by Student's t test using Instat3 software (GraphPad Software, San Diego, CA, USA). We used a two-tailed $P$ value assuming populations may have different standard errors. The data for dose-response experiments were analyzed by analysis of variance (ANOVA) followed by either Dunnett or Bonferroni multiple comparison tests. The data were considered significant only if the $P<0.05$, * indicates $P<0.05$, **, $P<0.01$ and ${ }^{* * *}, P<0.001$.

\section{Results}

BCNU decreases $A \beta$ levels dose-dependently in $\mathrm{CHO}$ cells Anecdotal observations in nursing homes that cancer survivors were less likely to be diagnosed with $\mathrm{AD}$ which was confirmed in multiple studies [25,26,30] strongly suggest an inverse relationship between cancer and AD. This compelling evidence led us to firmly believe that oncology drugs might be helpful in AD. Therefore, we screened a library of all the FDA-approved oncology drugs totaling 89 compounds obtained from $\mathrm{NCI} / \mathrm{NIH}$ [27] at a concentration of $10.0 \mu \mathrm{M}$ to determine their effects on $\mathrm{A} \beta$ levels by immunoprecipitation of $\mathrm{A} \beta$ in the $\mathrm{CM}$ and Western blotting. Interestingly, BCNU strongly decreased $A \beta$ levels in $\mathrm{CHO}$ cells in the initial screens (Figure 1A). Subsequent dose-response experiments confirmed that $\mathrm{BCNU}$ induced decreased $\mathrm{A} \beta$ levels in $\mathrm{CHO}$ cells (Figure $1 \mathrm{~B} \& 1 \mathrm{C}$ ). To test the effect of different concentrations of $\mathrm{BCNU}, \mathrm{CHO}$ cells stably expressing APP751WT (7WD10) were treated for 48 hours and the CM were immunoprecipitated with Ab9 antibody which recognizes an epitope within 1-16 amino acids of $A \beta$ peptide. This was followed by a Western blot detection of $A \beta$ using the $6 \mathrm{E} 10 / 82 \mathrm{E} 1$ mixture of antibodies which we have previously used for consistent detection of total A $\beta$ species $[28,29]$. Exposure of 7WD10 cells to BCNU decreased the secretion of $\mathrm{A} \beta$ starting at $5.0 \mu \mathrm{M}$ by $39 \%(P<0.05), 10.0 \mu \mathrm{M}$ by $51 \%(P<0.01)$ and $20 \mu \mathrm{M}$ by $63 \%(P<0.01)$ compared to cells treated with a structural analog as controls (Figure $1 \mathrm{~B}$ and $1 \mathrm{C}$ ). Thus, increasing the concentration of $\mathrm{BCNU}$ revealed a dose-dependent decrease in $A \beta$ levels, without altering the level of the holoprotein at any of the concentrations tested. These results demonstrate that $\mathrm{BCNU}$ inhibits $\beta / \gamma$-secretase mediated APP cleavage of WT APP.

In an effort to identify more potent carmustine analogs, we synthesized 12 carmustine structural derivatives and screened them for their effect on $\mathrm{A} \beta$ levels. The derivatives tested include 1-(2-chloroethyl)-3-hexylimidazolidin-2-one $\left(\mathrm{C}_{11} \mathrm{H}_{21} \mathrm{ClN}_{2} \mathrm{O} ; \mathrm{MW}, 232.7502\right), 1$-(2-chloroethyl)-3-(3-isopropylphenylimidazolidin-2-one $\left(\mathrm{C}_{14} \mathrm{H}_{19} \mathrm{ClN}_{2} 0\right.$; $\mathrm{MW}$, 266.7665), 1, 3-bis(2-chloroethylimidazolidin-2-one $\left(\mathrm{C}_{7} \mathrm{H} 12 \mathrm{Cl}_{2} \mathrm{~N}_{2} \mathrm{O}\right.$; MW, 232.7502), 1-(2-chloroethyl)-3-(3phenylimidazolidin-2-one $\left(\mathrm{C}_{11} \mathrm{H}_{13} \mathrm{ClN}_{2} 0 ; \mathrm{MW}, 224.6867\right)$, 1-(2-bromoethyl)-3-(2-chloroethylimidazolidin-2-one $\left(\mathrm{C}_{7} \mathrm{H}_{12} \mathrm{BrClN}_{2} \mathrm{O} ; \mathrm{MW}, 255.5400\right), 1$-(2-chloroacetyl)-3-(2chloroethyllimidazolidin-2-one $\left(\mathrm{C}_{7} \mathrm{H}_{10} \mathrm{Cl}_{2} \mathrm{~N}_{2} \mathrm{O}_{2}\right.$; MW, 225.0725), 1-(2-chloroethyl)-3-phenylimidazolidin-2thione $\left(\mathrm{C}_{11} \mathrm{H}_{13} \mathrm{ClN}_{2} \mathrm{~S}\right.$; MW, 240.7523), phenyl ethylamine $\left(\mathrm{C}_{19} \mathrm{H}_{25} \mathrm{~N}_{3} \mathrm{O} ; \mathrm{MW}, 311.20\right)$, cyclopentyl amine $\left(\mathrm{C}_{13} \mathrm{H}_{25} \mathrm{~N}_{3} \mathrm{O}\right.$; $\left.\mathrm{MW}, 239.20\right)$, butyl amine $\left(\mathrm{C}_{11} \mathrm{H}_{25} \mathrm{~N}_{3} \mathrm{O}\right.$; 

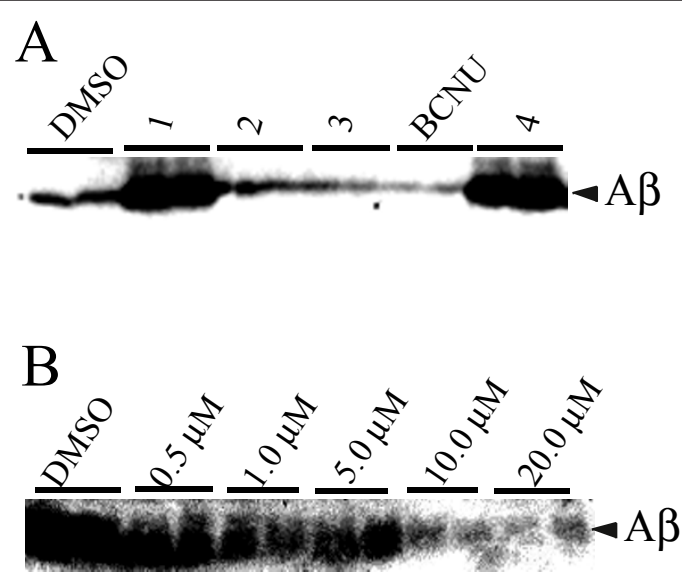

$\mathrm{D}$
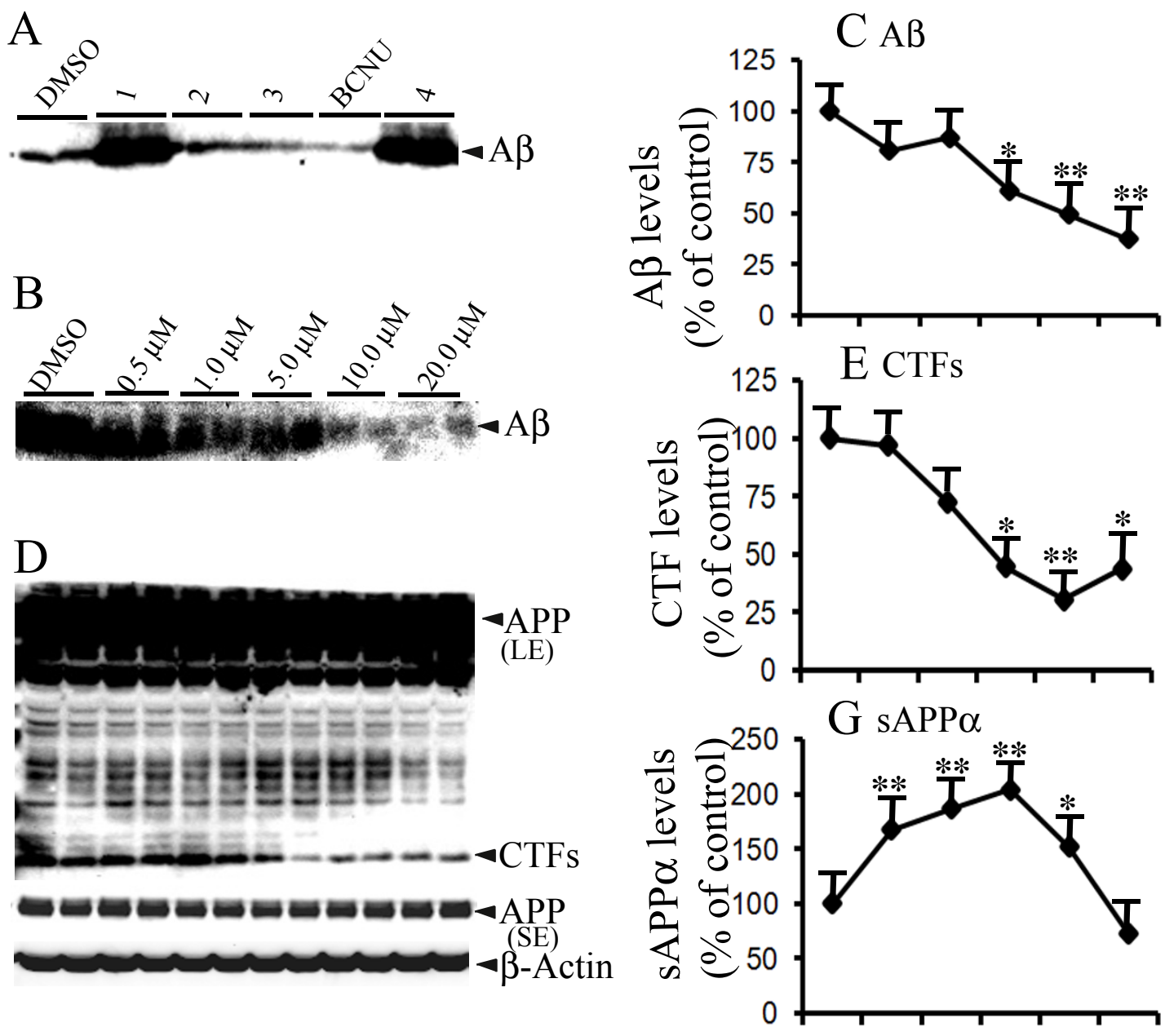

$\mathrm{F}$

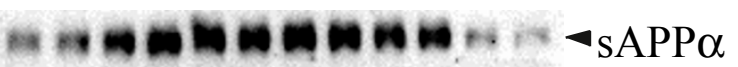

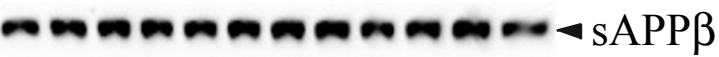

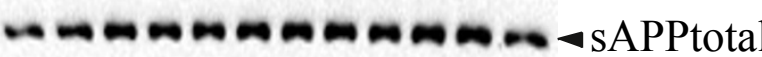

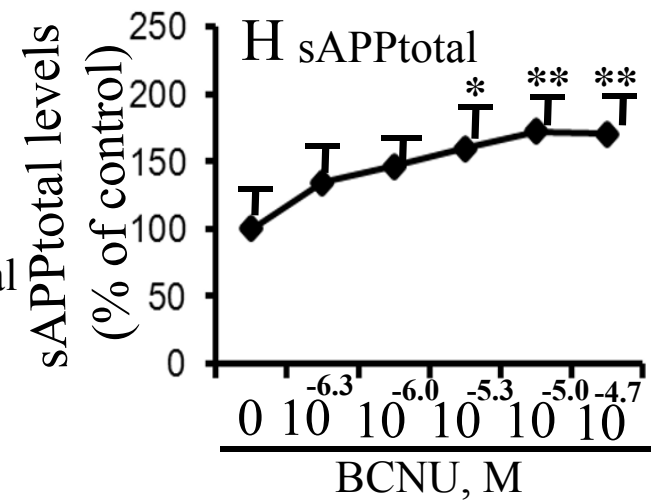

Figure 1 BCNU decreases $\mathbf{A} \beta$ and CTF levels in CHO cells stably expressing APP751WT (7WD10 cells). A) An initial screening of a library of oncology drugs used at $10.0 \mu \mathrm{M}$ identified carmustine (BCNU) as a potential anti-A $\beta$ drug, while drugs such as 1 and 4 increased $A \beta$ levels. The cells were exposed to the drugs for 48 hours and the conditioned media were immunoprecipitated for $A \beta$ and detected by immunoblots. B) 7WD10 cells were incubated with different concentrations of BCNU for 48 hours and the conditioned media were immunoprecipitated for A and detected by immunoblots. C) Quantitation of $A \beta$ levels by ImageJ revealed decreased $A \beta$ levels to $61 \%(P<0.05)$ at $5 \mu \mathrm{M}, 49 \%(P<0.01)$ at $10 \mu \mathrm{M}$ and $37 \%(P<0.01)$ at $20 \mu \mathrm{M}$ compared to controls. D) The lysates were used to detect c-terminal fragments (CTFs) and APP as well as actin as a loading control. E) CTF levels were also significantly decreased to $44 \%(P<0.05)$ at $5 \mu \mathrm{M}, 30 \%(P<0.01)$ at $10 \mu \mathrm{M}$ and $43 \%(P<0.05)$ at $20 \mu \mathrm{M}$ compared to controls. F) The conditioned media from B was subjected to immunoblotting to detect different species of sAPPs. G) sAPPa levels were increased to $167 \%(P<0.01)$ at $0.5 \mathrm{uM}, 186 \%(P<0.05)$ at $1 \mathrm{uM}, 204 \%(P<0.01)$ at $5 \mathrm{uM}$ and $152 \%(P<0.05)$ at $10 \mathrm{uM}$ compared to untreated cells. $\mathbf{H})$ sAPPtotal levels were increased to $159 \%(P<0.05)$ at $5 \mu \mathrm{M}, 172 \%(P<0.01)$ at $10 \mu \mathrm{M}$ and $170 \%(P<0.01)$ at 20 $\mu \mathrm{M}$ in $\mathrm{BCNU}$ treated cells compared to controls. For all samples, $\mathrm{n}=4 \pm \mathrm{SEM} .{ }^{*}, P<0.05,{ }^{* *}, P<0.01$ versus control by analysis of variance (ANOVA) followed by post-hoc test by Dunnett multiple comparisons. A 3 , amyloid $\beta$; APP, Alzheimer's precursor protein; BCNU, 1, 3 bis ( $2-$ chloroethyl)-1-nitrosourea; $\mathrm{CHO}$, Chinese hamster ovary; SEM, standard error of the mean. 
$M W, 215.20)$, piperidine $\left(\mathrm{C}_{13} \mathrm{H}_{25} \mathrm{~N}_{3} \mathrm{O} ; \mathrm{MW}, 239.20\right)$ and morpholine $\left(\mathrm{C}_{11} \mathrm{H}_{21} \mathrm{~N}_{3} \mathrm{O}_{3}\right.$; $\left.M W, 243.16\right)$. None of the derivatives were as potent as $\mathrm{BCNU}$.

BCNU decreases CTF levels dose-dependently in CHO cells To quantify APP-derived CTF levels, lysates were prepared from the same cells that were used for $A \beta$ quantitation after treatment with different concentrations of BCNU. CTFs were detected by Western blotting using CT15 antibody. Similar to A $\beta$ levels, CTF levels were also significantly decreased at $5.0 \mu \mathrm{M}(55 \%, P<0.05), 10.0 \mu \mathrm{M}(70 \%$, $P<0.01)$ and $20.0 \mu \mathrm{M}(56 \%, P<0.05)$ compared to untreated controls (Figure 1D and 1E). Thus, except for the first two lower concentrations, BCNU significantly decreased APP processing and CTF production, starting from $5.0 \mu \mathrm{M}$. These changes occurred without alterations in APP holoprotein which was also detected by the CT15 antibody. The decreased CTF levels are consistent with decreased $A \beta$ levels by $B C N U$ and indicate that $B C N U$ decreases amyloidogenic processing of APP in $\mathrm{CHO}$ cells.

\section{BCNU significantly increases levels of $\operatorname{sAPP} \alpha$ and sAPPtotal but not SAPP $\beta$}

To obtain an overall picture of APP metabolism under $\mathrm{BCNU}$ treatment, we further quantified the levels of secreted large extracellular $\mathrm{N}$-terminal domain truncated protein at the $\alpha$-site $(\mathrm{sAPP} \alpha)$ or at the $\beta$-site $(\mathrm{sAPP} \beta)$ as well as levels of sAPPtotal from the same CM used for $A \beta$ quantification. More than a one-fold increase was noted for sAPP $\alpha$ levels at some concentrations of BCNU applied for 48 hours, although we did not notice a strict dosedependent increase in sAPP $\alpha$ levels. The secretion of sAPP $\alpha$ was increased to $167 \%$ at $0.5 \mu \mathrm{M}(P<0.01), 186 \%$ $(P<0.05)$ at $1.0 \mu \mathrm{M}, 204 \%(P<0.01)$ at $5.0 \mu \mathrm{M}$ and $152 \%$ $(P<0.05)$ at $10.0 \mu \mathrm{M}$ (Figure $1 \mathrm{~F}$ and $1 \mathrm{G})$. For some unknown reason, $\mathrm{sAPP} \alpha$ levels were not altered at the highest concentration of $20.0 \mu \mathrm{M}$ tested, although $\mathrm{A} \beta$ levels were significantly decreased. The maximum increase (204\%) was noted at $5.0 \mu \mathrm{M}$ concentration. Similarly, the levels of sAPPtotal were increased by $159 \%(\mathrm{P}<0.05)$ at $5.0 \mu \mathrm{M}, 172 \%(P<0.01)$ at $10.0 \mu \mathrm{M}$ and $170 \%(P<0.01)$ at $20.0 \mu \mathrm{M}$ in BCNU-treated cells (Figure $1 \mathrm{~F}$ and $1 \mathrm{H}$ ). On the other hand, there were no significant alterations in the levels of sAPP $\beta$ at any of the BCNU concentrations tested. The sAPP $\alpha$ levels were detected using 6E10 antibody which recognizes an epitope within the 1-17 amino acid of the A $\beta$ domain of APP. sAPPtotal was detected by the 63G antibody whose epitope lies within the mid region of APP. Taken together, decreased levels of A $\beta$ and CTFs and increased release of sAPP $\alpha$ and sAPPtotal in the CM clearly indicate that $\mathrm{BCNU}$ may decrease amyloidogenic processing of APP by increasing $\alpha$-secretase mediated cleavage of APP thereby reducing the APP substrate available for cleavage by BACE enzyme.

\section{BCNU increases immature APP at the cell surface}

As endocytosis of surface APP is required for $A \beta$ generation [31,32], we next examined whether BCNU treatment altered surface levels of APP. To do this, all surface proteins were labeled with biotin and immunoprecipitated with antibiotin antibody. Results showed that BCNUtreated cells accumulated immature APP by more than one-fold at the cell surface compared to untreated cells $(P<0.001)$, while there was no change in the surface levels of mature APP (Figure 2A and 2B). Next, to test whether decreased amyloidogenic processing of APP is due to changes in turn-over of APP, we performed cycloheximide chase experiments. Confluent 7WD10 cells in six-well plates treated with or without BCNU were incubated with $100 \mathrm{mg} / \mathrm{ml}$ of cycloheximide to inhibit de novo synthesis of APP. This was followed by quantitation of steady state levels of APP holoprotein by Western blots at different time points up to two hours based on our previous experience that the calculated half-life of APP was about one hour [28]. The results did not reveal significant differences in the levels of APP at any of the time points tested between untreated and BCNU-treated cells (Figure 2C). This suggests that BCNU does not affect the half-life of APP and its stability. The decreased levels of $A \beta$ and CTFs induced by BCNU treatment, therefore, might result from increased immature APP at the cell surface leading to reduced endocytosis of APP which is necessary for cleavage of APP by secretases for A $\beta$ production $[31,32]$.

\section{BCNU does not inhibit secretases}

APP is cleaved by sequential actions of $\beta$ - and $\gamma$-secretases to release $A \beta$ and, therefore, compounds that reduce $A \beta$ generation can be expected to inhibit secretases. Therefore, we tested whether BCNU inhibits any of the secretases. To our surprise the activities of both $\beta$ - and $\gamma$-secretases were not affected by BCNU even at concentrations as high as $40 \mu \mathrm{M}$ of BCNU (Figure 3A). Similarly, we did not notice any change in the activities of ADAM 17 or ADAM 10 (Figure 3B), which cleaves APP at the $\alpha$-site. Thus, BCNU appears to decrease A $\beta$ generation independent of secretases, probably by simply altering the trafficking of APP.

\section{Cytotoxicity of BCNU measured by LDH release and MTT reduction}

The cytotoxicity of BCNU was determined by two independent enzyme-based assays by colorimetric detection using neuron-derived neuro-2a (N2a) cells. The LDH release assay revealed $\mathrm{BCNU}$ was nontoxic up to $20 \mu \mathrm{M}$ and was toxic only at $80 \mu \mathrm{M}(69.5 \%, P<0.01)$ and $240 \mu \mathrm{M}$ $(49 \%, P<0.01)$ (Figure $4 \mathrm{~B})$. To confirm these results by another method, we used CM from the cells incubated with different concentrations of BCNU to quantify the 


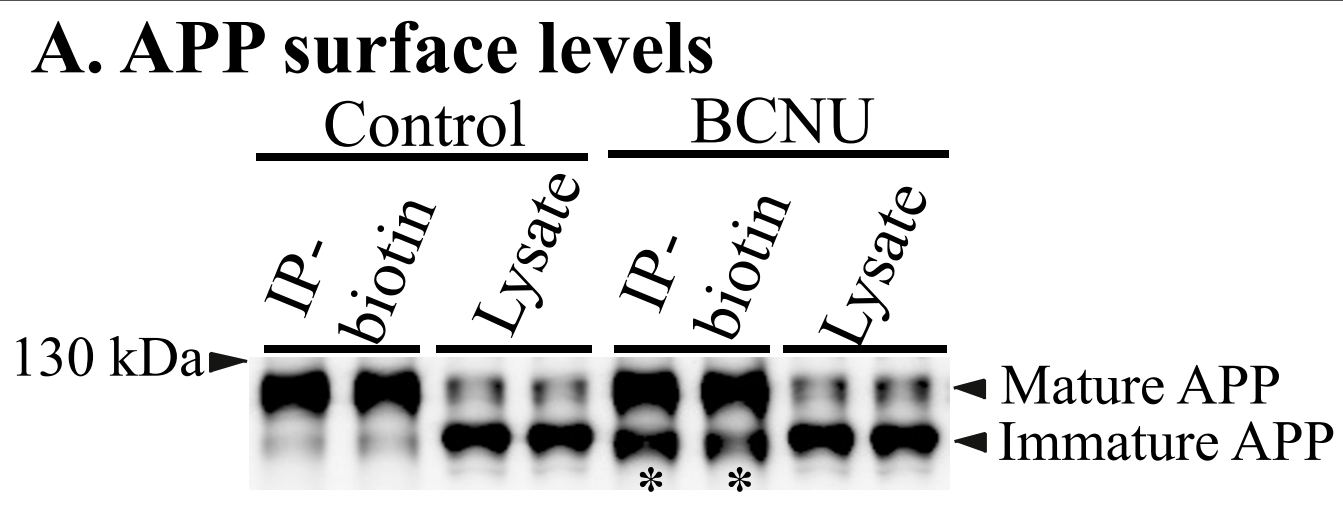

B. Ratio of surface to total APP

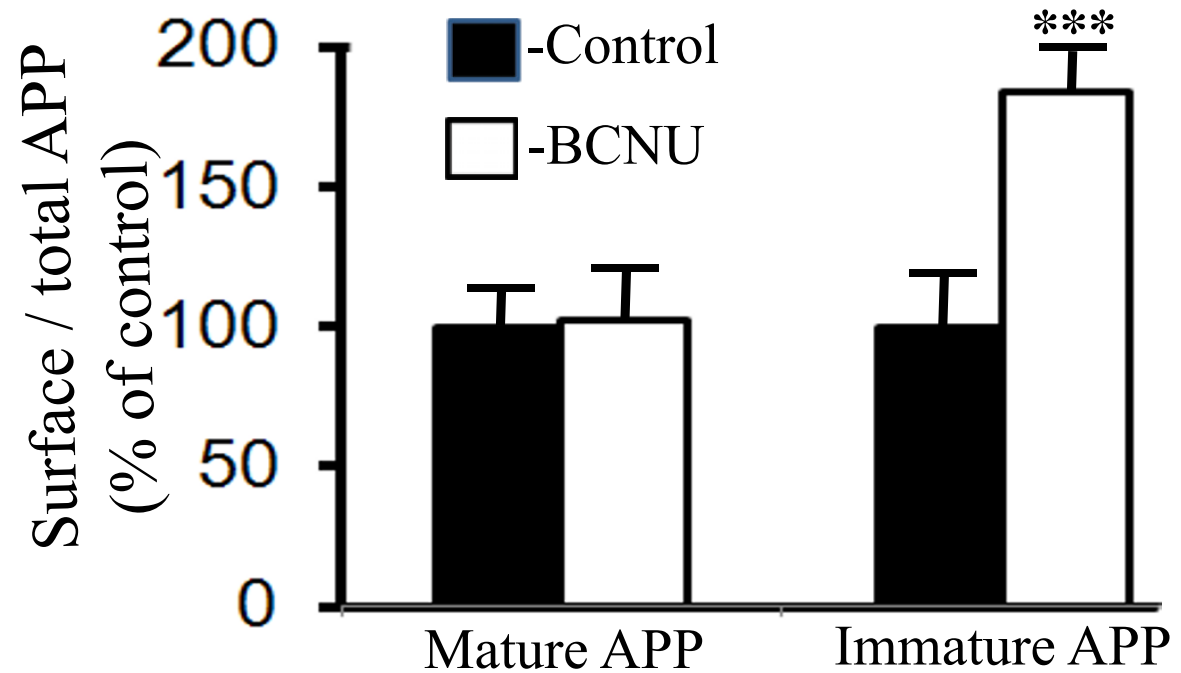

\section{APP stability}

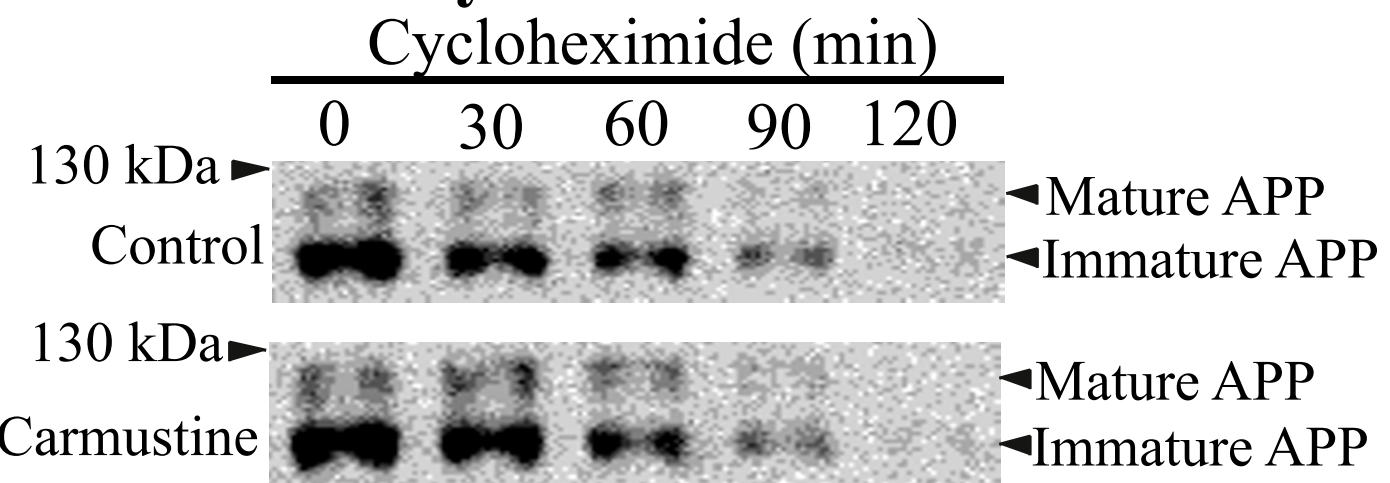

Figure 2 BCNU increases surface levels of immature APP. A) Surface biotinylation and biotin immunoprecipitation experiments showed significantly increased surface levels of immature APP in BCNU-treated 7WD10 cells compared to untreated cells. B) Quantitation of the signal in A) revealed increased surface to total APP levels for immature APP by $184 \%$ but the levels of mature APP were unaltered. C) Treatment of 7WD10 cells with BCNU at 10.0 uM concentration followed by cycloheximide chase at indicated time points did not alter APP half-life or stability. For all samples, $\mathrm{n}=4 \pm \mathrm{SEM}$. ${ }^{* *}, P<0.001$ versus controls by t test. APP, Alzheimer's precursor protein; BCNU, 1, 3 bis (2-chloroethyl)-1- 


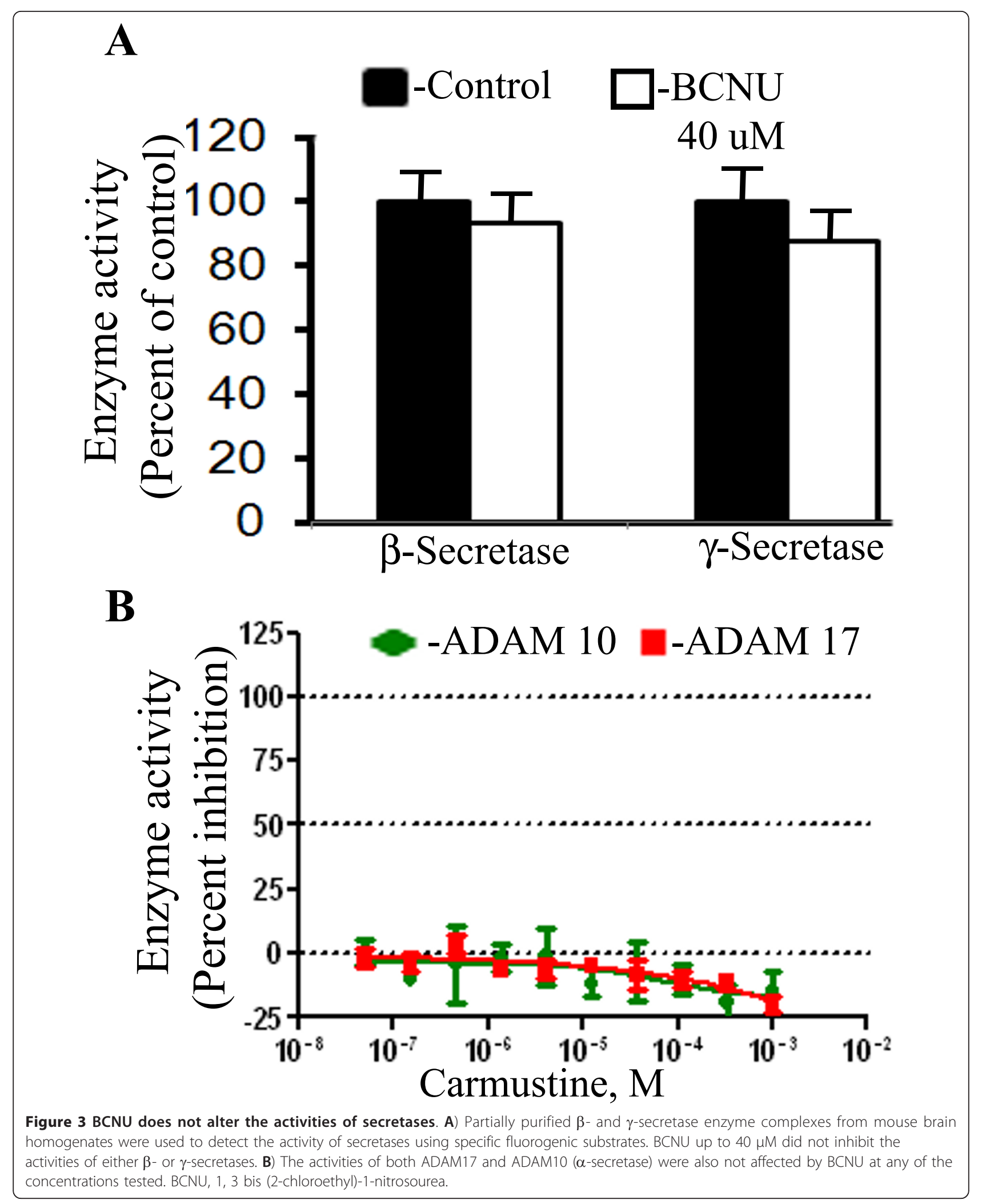


reduction of the MTT substrate. The MTT reduction assay reproduced the results of the $\mathrm{LDH}$ assay in that BCNU was non-toxic up to a concentration of $20 \mu \mathrm{M}$. However, BCNU incubation at $80 \mu \mathrm{M}(50 \%, P<0.01)$ and $240 \mu \mathrm{M}(45 \%, P<0.01)$ was significantly toxic at each concentration (Figure 4A). Thus, it is interesting to note that $\mathrm{BCNU}$ is toxic to the neuronal cell line only at high concentrations but not at concentrations that decreased $A \beta$ levels.

\section{Chronic BCNU administration decreases plaque burden in mice}

Although BCNU decreased $\mathrm{A} \beta$ production in cell cultures, amyloid plaques in the brain are more relevant to neurodegeneration in AD. Therefore, to verify whether decreased amyloidogenic processing of APP by BCNU observed in cell cultures is translated in vivo into decreased plaque burden, mice overexpressing APP with Swedish mutation and PS1 with $\triangle \mathrm{E} 9$ deletion were used as a robust mouse model for $A \beta$ plaques (APdE9) as these mice develop a modest amount of amyloid plaques as early as six months of age. Overall plaque burden was calculated as the ratio of 'the area occupied by plaques to the total region area', which was clearly decreased by about $81 \%(P<0.01)$ in BCNU-treated mice compared to saline-treated mice (Figure $5 \mathrm{~A}, \mathrm{~B}$ and $5 \mathrm{C}$ ). A representative histology section for saline- or BCNU-treated mice is shown in Figure $5 \mathrm{~A}$ and $5 \mathrm{~B}$ at comparable brain levels. The total plaque numbers were reduced only by $26 \%$ (Figure 5D, $P<0.05$ ). However, when the plaques were counted based on their size, those plaques which measured more than 1.0 square micron decreased by $39 \%$ (Figure 5E, $P<0.05$ ) and those measuring above 3.0 square microns decreased by $41 \%$ (Figure $5 \mathrm{~F}, P<$ $0.05)$ in the BCNU-treated mice compared to the salinetreated mice. Highly decreased plaque burden and a modest reduction in plaque numbers in BCNU-treated mice indicates that BCNU decreases the severity of plaques by reducing larger plaques. The decreased amyloid plaque burden following chronic BCNU administration in mice is consistent with decreased amyloidogenic processing of APP and A $\beta$ levels observed in cell cultures (Figure 1A, B and $1 \mathrm{C}$ ).

\section{BCNU decreases levels of A 340 and CTFs and increases sAPP $\alpha$ in mouse brains}

To test whether the decrease in amyloid plaques by BCNU was due to a decrease in $A \beta$, we quantified the levels of $A \beta 40$ in the mouse brains by sandwich ELISA using $A \beta$ specific antibodies. Exposure of BCNU even just for two months resulted in a $75 \%$ reduction in the levels of $A \beta 40$ (Figure 6B), which correlates well with the amount of reduction in amyloid plaques. Similar to the effect in cell cultures, CTF levels were also reduced in the brains after
BCNU treatment by 39\% $(P<0.01)$ (Figure 6C). Conversely, the levels of sAPP $\alpha$ were increased by $45 \%(P<0.01)$ (Figure 6D). Thus, BCNU-induced changes in APP metabolites observed in cell cultures were confirmed in vivo in the mouse brains.

\section{BCNU is rapidly metabolized in mice}

In order to correlate the drug concentrations in the brain that are required to reduce amyloidogenic processing of APP and plaque burden, we quantified BCNU levels in the brain by liquid chromatography with UV detection. At least three mice were tested for each of 5 and 20 minute time points following tail vein injection. Surprisingly, we failed to detect any BCNU at either time point. Direct incubation of $\mathrm{BCNU}$ in the blood and brain homogenates confirmed that $\mathrm{BCNU}$ was rapidly degraded with no trace of the compound in the brain homogenates within 30 minutes (Figure 7A), although BCNU could be detected up to 30 minutes in the blood (Figure 7B). These results suggest that $\mathrm{BCNU}$ is rapidly metabolized and the biological effect exerted on $A \beta$ levels could result from the action of one of the metabolites. In fact, the distribution and clearance of BCNU in both human and animals have been extensively studied. BCNU is a very unstable compound which undergoes both in vitro and in vivo spontaneous degradation to isocyanate and the chloroethylodiazohydroxide ion, which then is degraded to the chloroethylocarbonic ion and others [33,34]. Careful analysis of the chromatograms of brain homogenates revealed the presence of several metabolites, labeled A to $\mathrm{E}$, which we could identify in addition to several others which we could not identify (Figure 8A). We detected only a very small peak for the parent compound, BCNU, labeled $\mathrm{F}$ in the chromatogram (Figure 8A). The names and chemical structures of identified metabolites with their molecular weights are shown in Figure 8B. Such metabolites might actually be responsible for decreasing A $\beta$ levels and plaque burden.

\section{BCNU suppresses microglial activation}

In order to understand whether BCNU-mediated decreased plaque burden results from an increased number of activated microglia as previously shown for some oncology drugs, we quantified the number of activated microglia by staining brain sections with anti-Iba1 antibody. On the contrary, as shown in Figure 9A and 9C, chronic BCNU treatment resulted in a lower number of Iba1-positive microglia in the hippocampus $(30 \%, P<$ $0.05)$. Similarly we observed a $44 \%(P<0.01)$ lower number of Iba1-positve microglia in the motor cortex of BCNU-treated mouse brains as compared to saline-treated controls (Figure 9B and 9C). Thus, BCNU, in contrast to other oncology drugs, reduces microglial activation. This may even have a positive effect on the brain since activated 


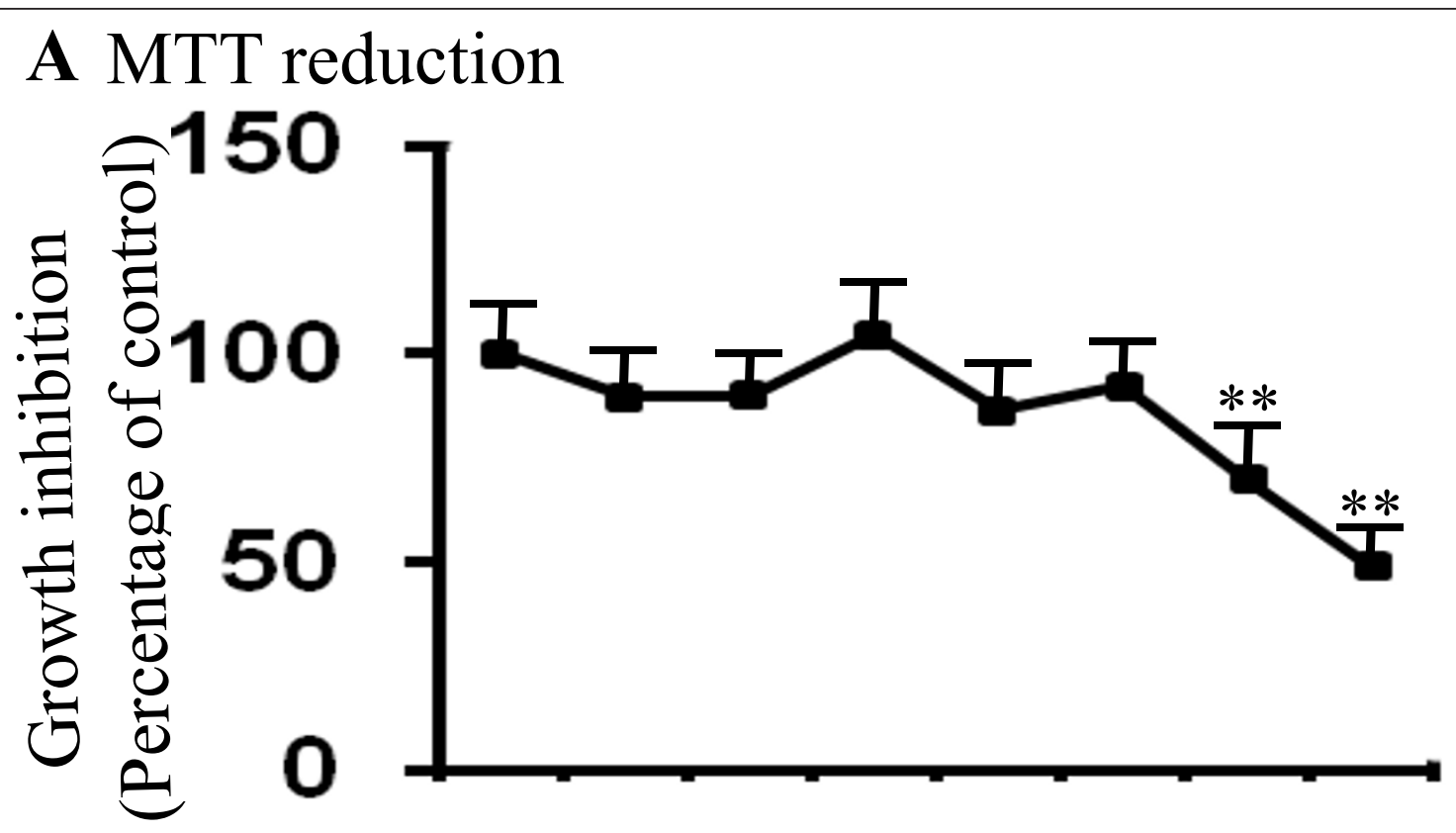

B LDH release

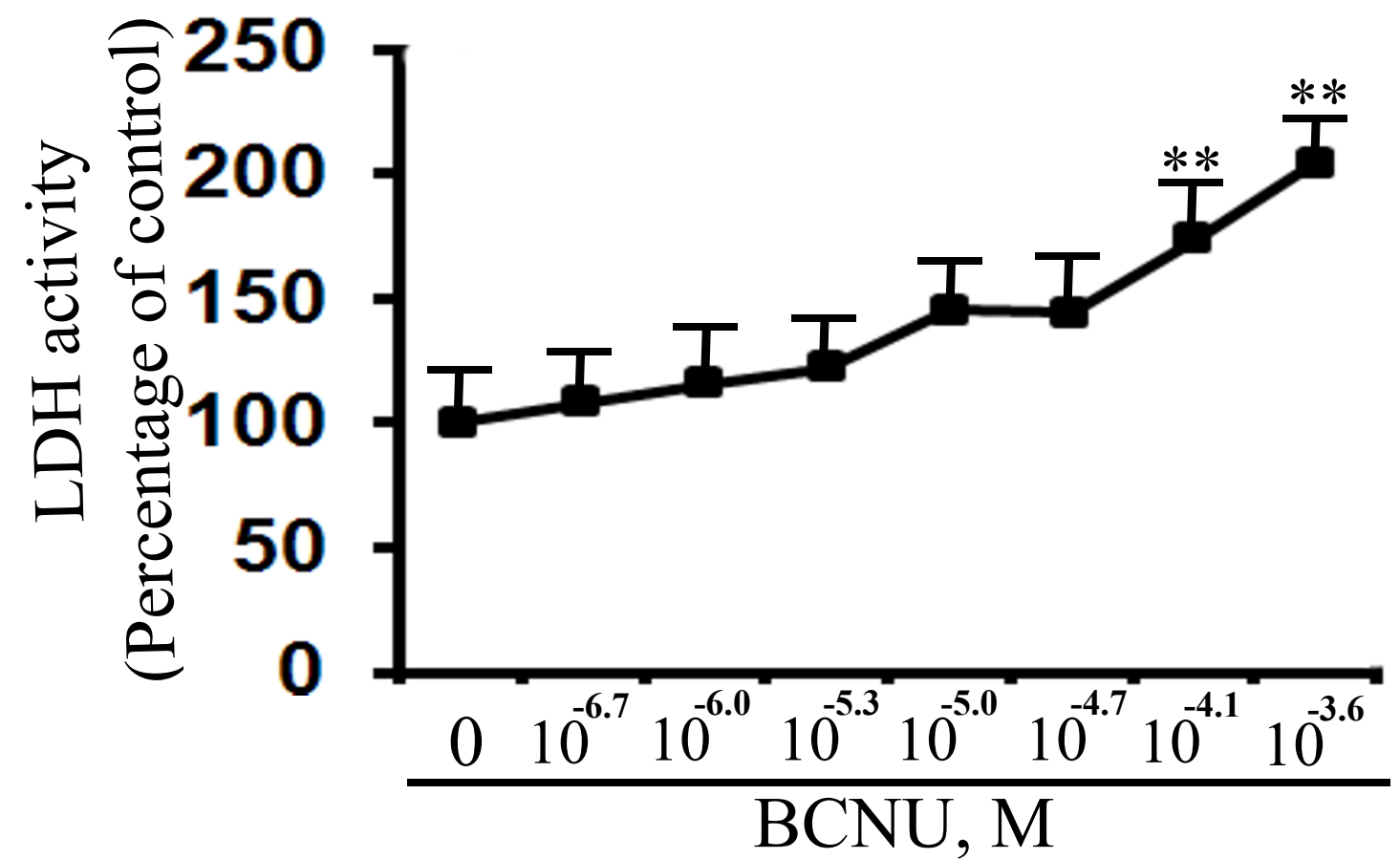

Figure 4 BCNU is cytotoxic only at high concentrations in Neuro-2a (N2a) cells. A) LDH release was measured as an indicator of cytotoxicity after incubation with different concentrations of BCNU as indicated. BCNU was not toxic up to $20 \mu \mathrm{M}$ and significant cytotoxicity was observed only at $80 \mu \mathrm{M}(P<0.01)$, and120 $\mu \mathrm{M}(P<0.01)$. B) The MTT reduction assay also indicated significant toxicity only at $80 \mu \mathrm{M}(69 \%$, $P<0.01)$ and $240 \mu \mathrm{M}(48.7 \%, P<0.001)$ but BCNU was nontoxic up to $20 \mu \mathrm{M}$. For all samples, $\mathrm{n}=4 \pm \mathrm{SEM}$. ${ }^{* *}, P<0.01$ versus untreated controls by analysis of variance (ANOVA) followed by post-hoc test by Dunnett multiple comparisons. BCNU, 1, 3 bis (2-chloroethyl)-1nitrosourea; LDH, lactate dehydrogenase; MTT, 3-(4, 5-dimethylthiazol-2-yl)-2, 5-diphenyltetrazolium bromide. 


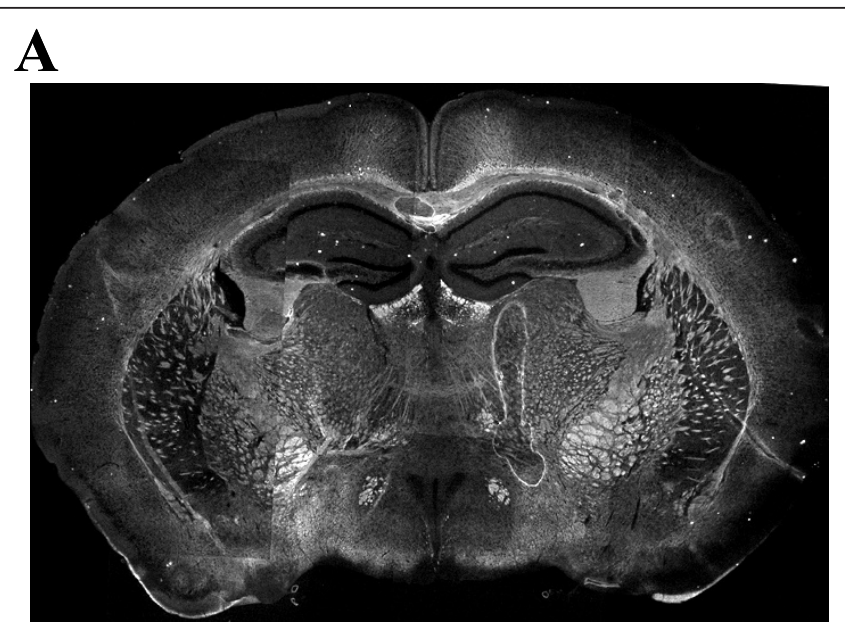

B

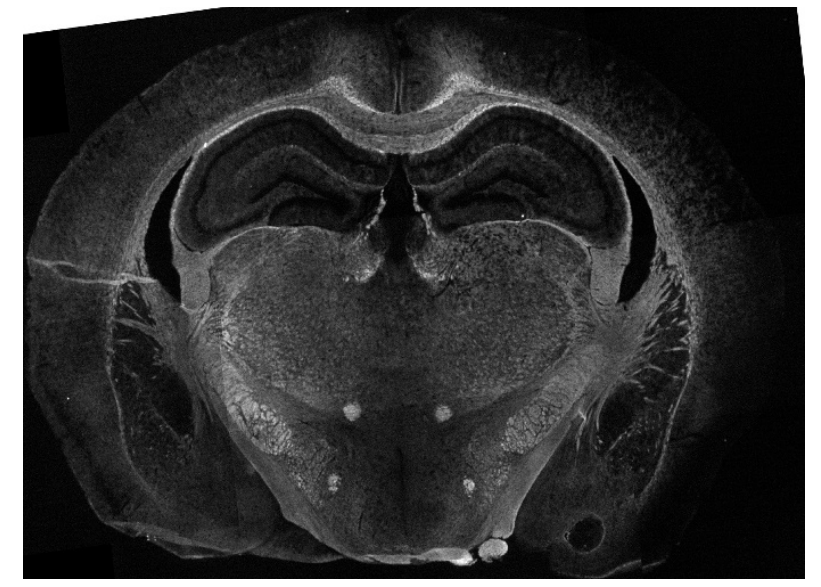

E

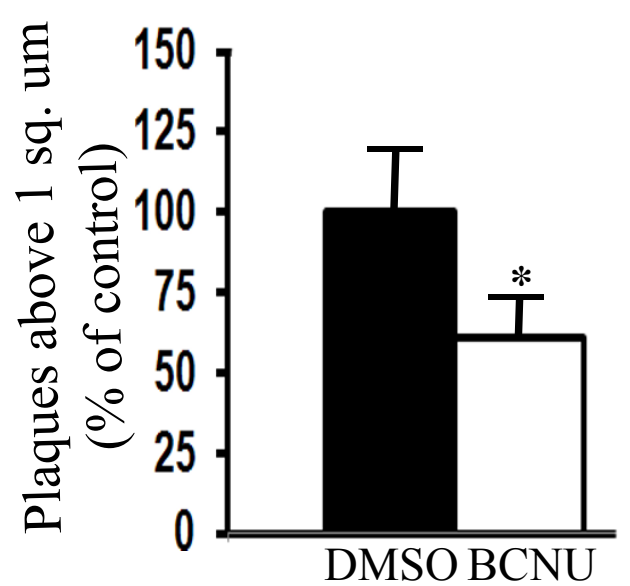

C

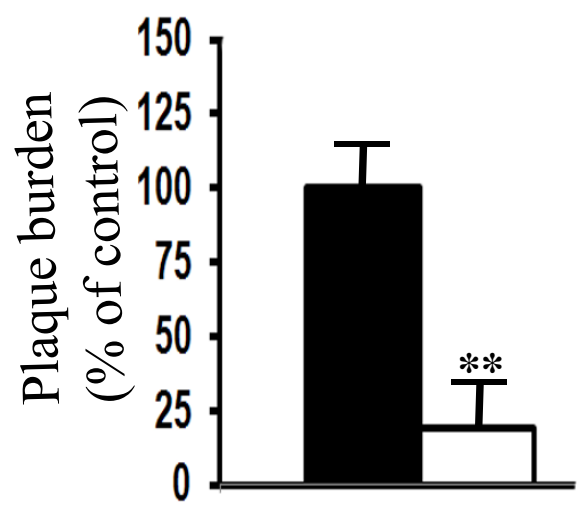

D
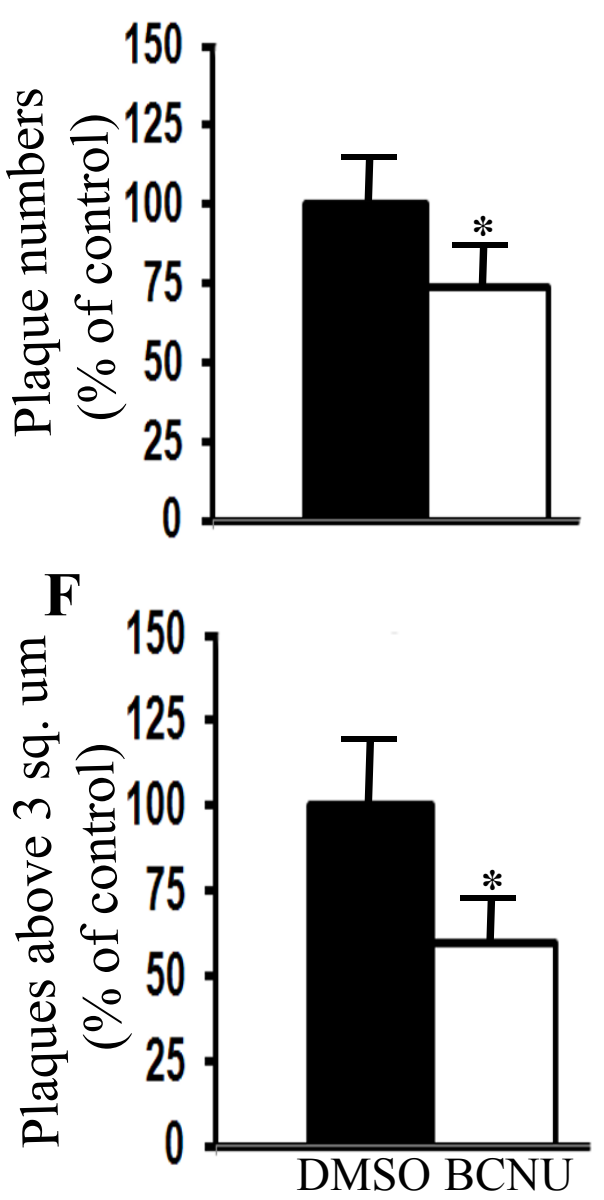

Figure 5 Chronic BCNU administration decreases amyloid plaque burden in mice. APdE9 mice were treated daily by intraperitoneal injections with BCNU starting from four months to six months of age for 60 days. Amyloid plaques were stained by thioflavin $\mathrm{S}$ in coronal brain sections. A) A representative section with amyloid plaques in vehicle-treated mice at six months of age is shown. B) A representative section of brain showing decreased amyloid plaques in mice treated with BCNU is shown. C) Quantitation by ImageJ analysis showed decreased plaque burden by $81 \%(P<0.01)$ when compared to vehicle-treated APdE9 mice. D) The total number of plaques was reduced by $26 \%(P<0.05)$. E) Plaques measuring more than 1.0 square micron were reduced by $39 \%(P<0.05)$. F) Plaques measuring more than 3.0 square microns decreased by $41 \%(P<0.05)$. In each group, $n=6, \pm$ SEM. ${ }^{*}, P<0.05$, ${ }^{* *}, P<0.01$ in BCNU-treated APdE9 mice versus vehicle-treated APdE9 mice by student's t test. BCNU, 1, 3 bis (2-chloroethyl)-1-nitrosourea; SEM, standard error of the mean. 


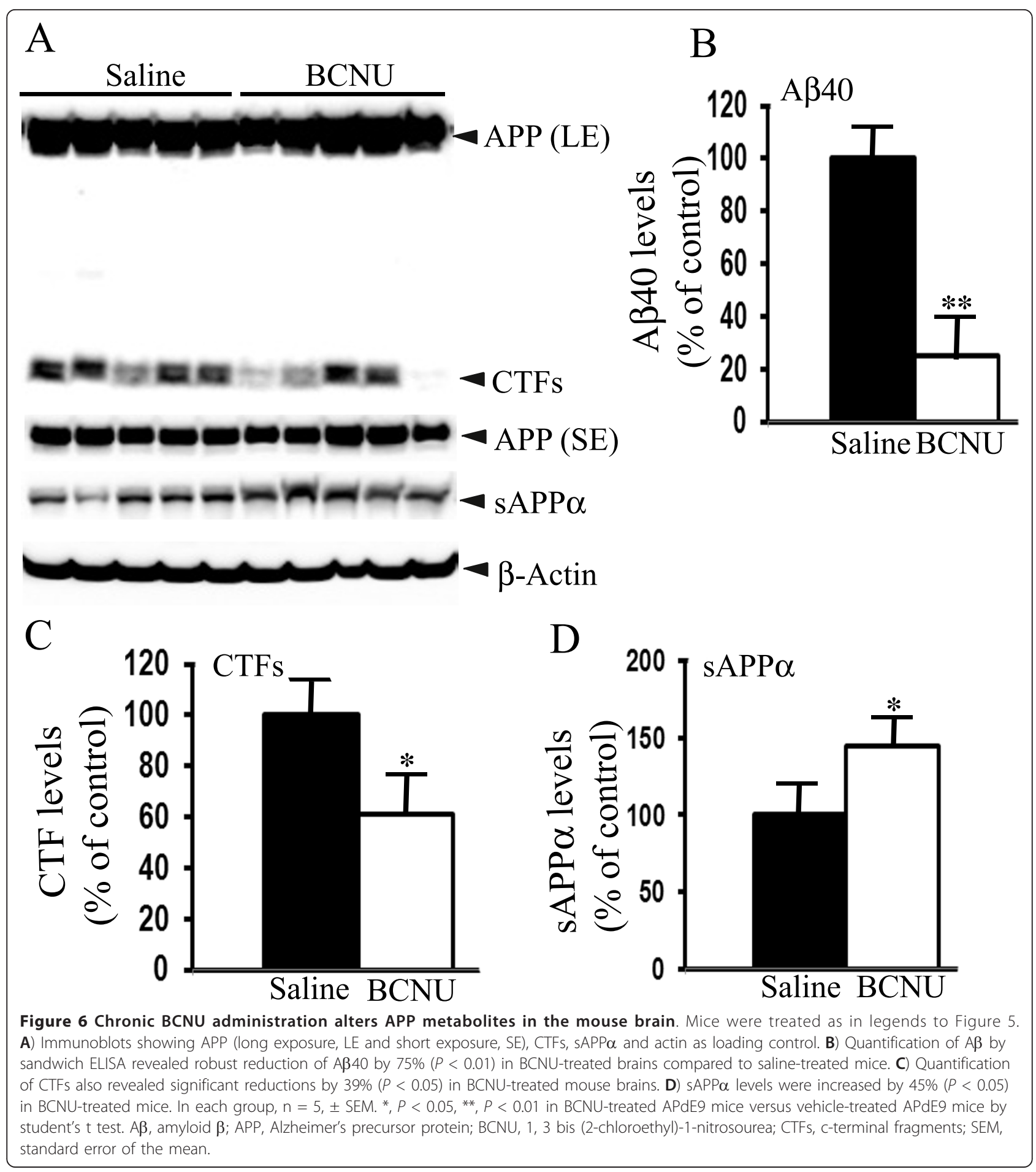

microglia is pro-inflammatory and may lead to neurodegeneration.

BCNU increases transforming growth factor $\beta$ levels In a study using mRNA differential display, BCNU has been shown to increase the expression of a gene encoding the latent transforming growth factor-binding protein
1 (LTBP-1) by three-fold suggesting that BCNU might increase transforming growth factor- $\beta 1$ (TGF- $\beta 1$ ) signaling [35], which is known to play a pivotal role in APP metabolism. Therefore, to understand the possible molecular mechanism for the reduced amyloidogenic processing of APP by BCNU, we quantified the levels of TGF $\beta$ protein released into the $\mathrm{CM}$ and also in the lysates after 


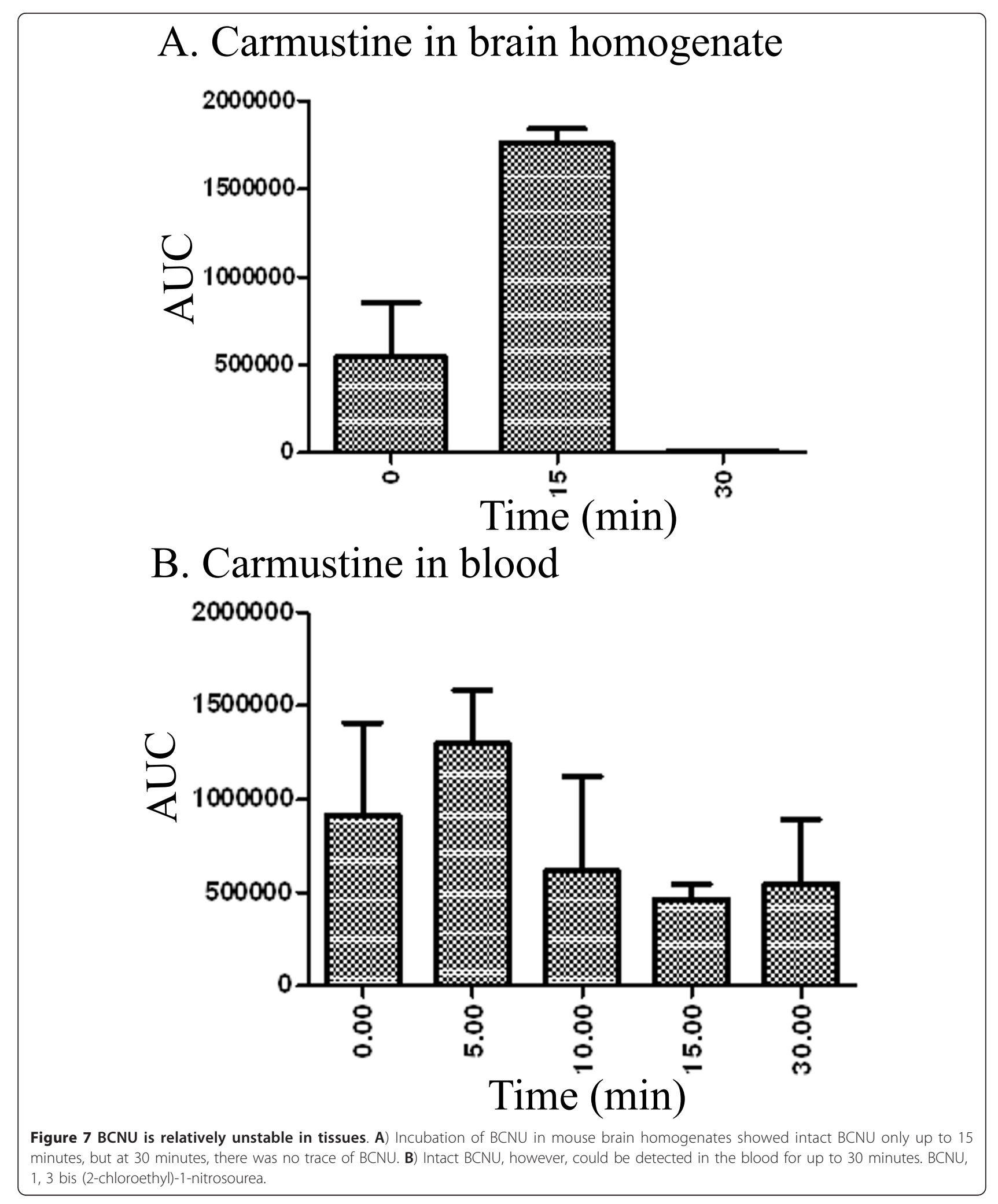




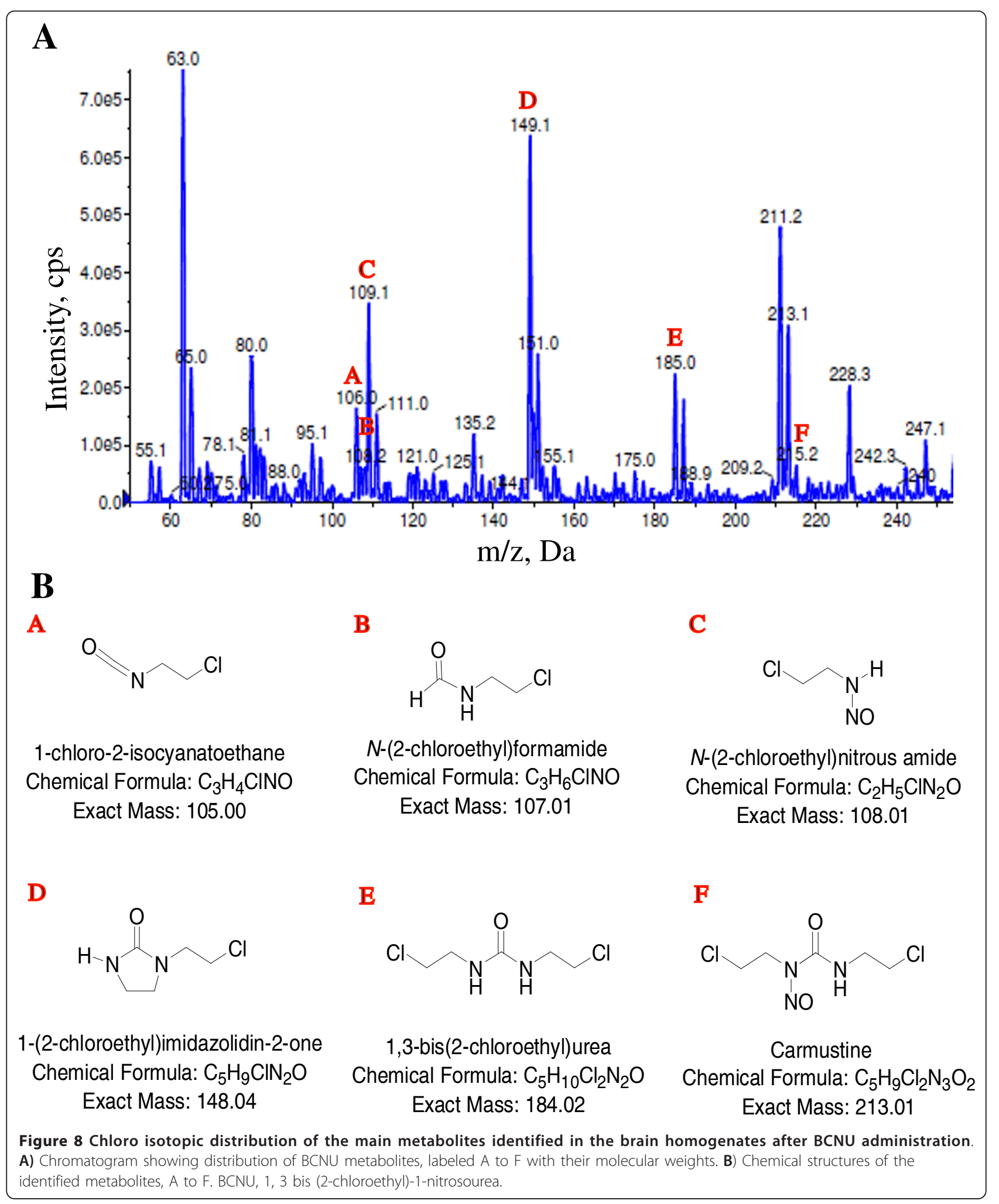




\section{A Hippocampus}

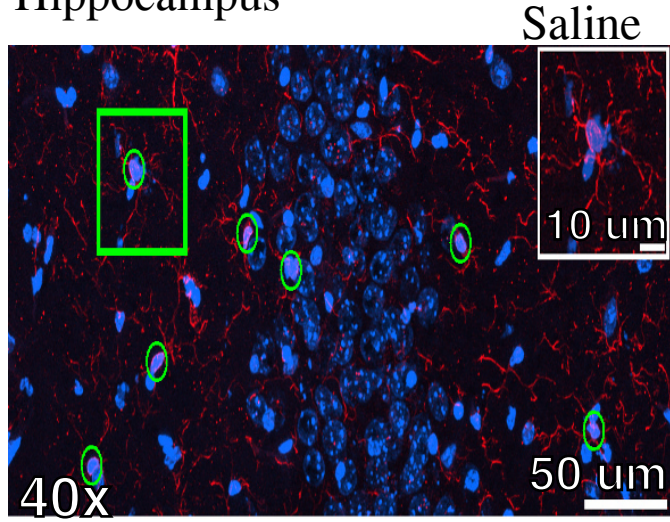

B Motor cortex

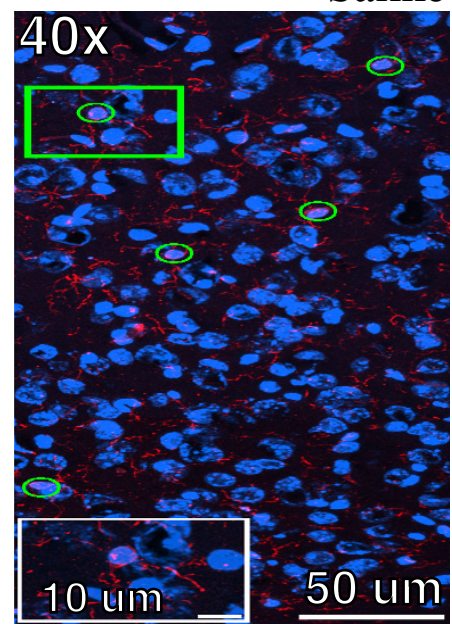

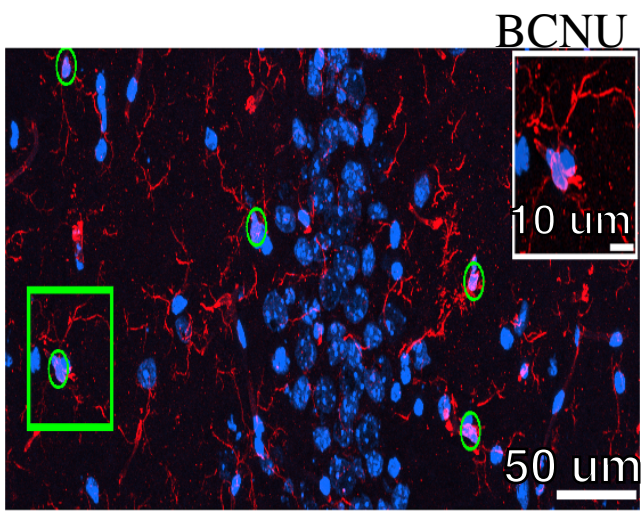

BCNU

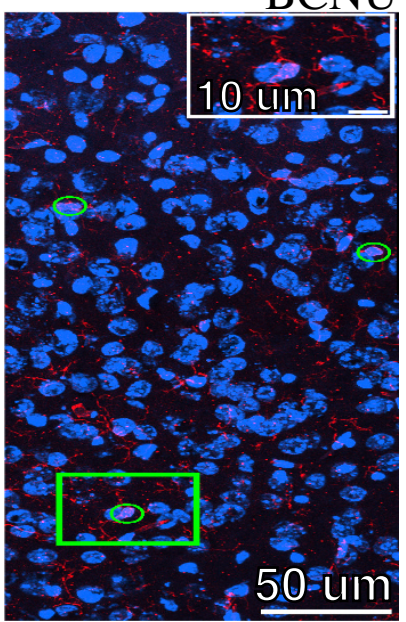

C Quantitation

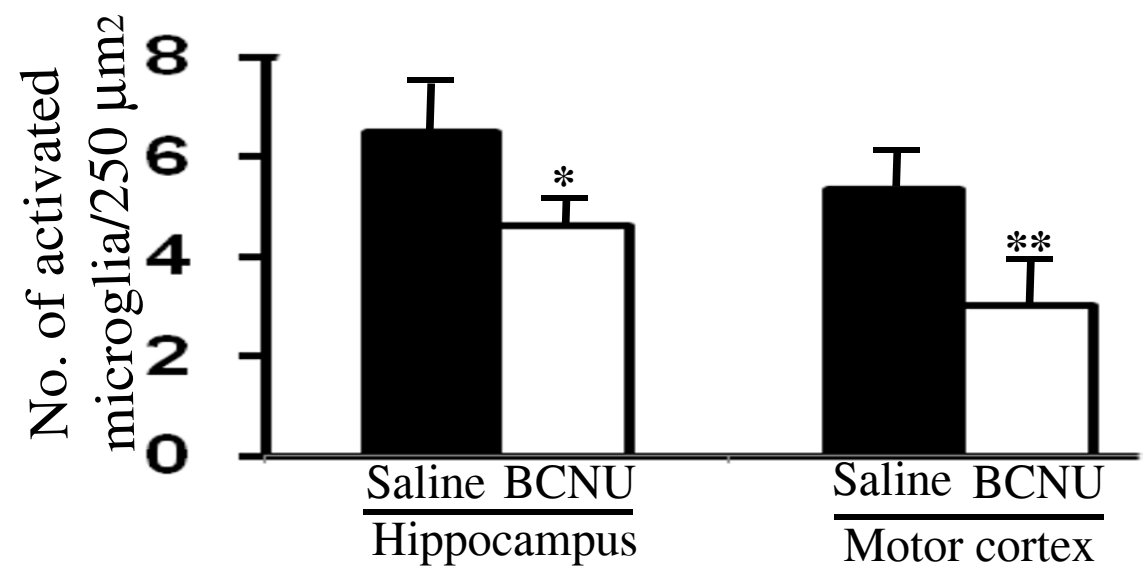

Figure 9 The number of activated microglia is reduced in both the hippocampus and motor cortex in BCNU-treated mouse brains A) Iba1 positive activated microglia (red) in the CA3 region of the hippocampus shown in saline- or BCNU-treated mouse brains. The nuclei were stained with DAPI (blue) and the merged images (yellow) show microglia positive for Ibal, which were counted. B) Iba1 positive activated microglia in the motor cortex. The magnification and the scale bars are indicated. The inset in both A and B is to show an enlarged microglia positive for both DAPI and Iba1. C) Quantification showed 30\% $(P<0.05)$ and $44 \%(P<0.01)$ reduced numbers of activated microglia in the hippocampus and motor cortex, respectively. All values are mean $\pm \mathrm{SEM}, \mathrm{n}=5$ in each group. ${ }^{*}, P<0.05,{ }^{*}, P<0.01$ in $\mathrm{BCNU}$-treated APdE9 mice versus saline-treated APdE9 mice by student's t test. BCNU, 1, 3 bis (2-chloroethyl)-1-nitrosourea; DAPI, 4',6-diamidino-2-phenylindole; SEM, standard error of the mean. 
cells were treated with different concentrations of BCNU. Interestingly, TGF $\beta$ levels were increased at $10.0 \mu \mathrm{M}$ (92\%, $P<0.001)$ and $20.0 \mu \mathrm{M}(73 \%, P<0.01)$ compared to untreated cells (Figure 10A and 10B). TGF $\beta$ levels were also significantly increased in the lysates at the same concentrations of $10.0 \mu \mathrm{M}(149 \%, P<0.05)$ and $20.0 \mu \mathrm{M}(154 \%, \mathrm{P}<0.01)$. The increased levels of TGF $\beta$ at the higher concentrations of $\mathrm{BCNU}$ are consistent with decreased $A \beta$ levels at these concentrations.

\section{Discussion}

In this study, we have shown for the first time that $\mathrm{BCNU}$ treatment can reduce amyloidogenic processing of APP and A $\beta$ generation in cell cultures as well as in a mouse model of AD. Although BCNU is known to be a cytotoxic compound, it reduced $A \beta$ levels at non-toxic concentrations. Two other oncology drugs have recently been shown to significantly reduce $\mathrm{A} \beta$ generation. Imatinib (Gleevec) has been shown to reduce $\mathrm{A} \beta$ by $50 \%$ at $10.0 \mu \mathrm{M}$ concentration [36,37], similar to the magnitude observed for BCNU in the present study, but the advantage of $\mathrm{BCNU}$ is that it can pass through the $\mathrm{BBB}$ [38], while Gleevec cannot [39]. Bexarotene, another oncology drug, reduced amyloid plaques by $50 \%$ within 72 hours after oral administration [40]. Although BCNU reduced plaque burden by $81 \%$, much more than did bexarotene, it took two months of intraperitoneal administration unlike bexarotene which rapidly cleared within a few days of oral treatment. Thus, BCNU falls between Gleevec and bexarotene as a favorable $A \beta$ reducing drug.

It is noteworthy that $B C N U$ decreased $A \beta$ levels from CHO cells stably expressing APP751WT (7WD10 cells), as the majority of cases of sporadic AD patients carry wild-type APP. Thus, BCNU decreased A $\beta$ generation from both the predominantly neuronal form, APP695, as well as the non-neuronal form, APP751, considering the results in 7WD10 cells as well as mouse brains. Wild-type APP and APP with Swedish mutation are known to be processed and trafficked differently. The most important observation that we made was the increased ratio of mature APP versus immature APP at the cell surface. The molecular mechanisms that regulate APP maturity, trafficking and $A \beta$ generation are complex. Newly synthesized immature APP in the endoplasmic reticulum (ER) is first $\mathrm{N}$-glycosylated at the ER and after its exit undergoes O-glycosylation at the Golgi complex attaining maturity. In the secretory pathway mature APP is then sorted to the plasma membrane where it undergoes endocytosis, a necessary step for $A \beta$ production $[31,32]$. Thus, BCNU reduces $A \beta$ generation probably by reducing endocytosis of APP from the cell surface. But A $\beta$ can also be produced in the secretory pathway. If APP undergoes $\alpha$-cleavage presumably in the secretory pathway in the trans-Golgi network, it can drastically reduce $A \beta$ generation. Increased
sAPP $\alpha$ levels in the present study also suggests that BCNU might influence $A \beta$ generation through increased $\alpha$-secretase mediated processing of APP. Decreased A $\beta$ levels induced by BCNU may be a cumulative effect of both pathways. Interestingly, several pharmacological agents have been shown to reduce $A \beta$ generation by attenuating APP maturity. For example, protein kinase A (PKA) inhibitors have been shown to reduce $A \beta$ production by accumulating immature APP [41]. Inhibitors of acyl-coenzyme A cholesterol acyl transferase (ACAT) also reduced A $\beta$ production by decreasing the ratio of mature to immature APP [42]. Similarly, zinc [43] and O-glycosylation inhibitors [44], both of which retarded APP maturation, also reduced $A \beta$ generation. Since $B C N U$ did not affect the activities of any of the secretases, reduced $A \beta$ generation most likely results from altered trafficking of APP due to accumulation of immature APP. Protein overexpression studies also provide indirect evidence that maturity and trafficking of APP to the cell membrane affects A $\beta$ production. Overexpression of growth arrest-specific 1 gene also reduces $A \beta$ generation by inhibiting glycosylation of APP thereby enhancing accumulation of immature APP in the plasma membrane [45]. Collectively, these data provide compelling evidence that $B C N U$ decreases $A \beta$ production by retarding APP maturation thereby altering its trafficking and cleavage. It is also possible that BCNU decreased A $\beta$ levels through the TGF $\beta$ pathway. Genetic polymorphisms at +10 CC genotype on TGF $\beta$ has been shown to be associated with reduced serum levels of TGF $\beta$ in mild cognitive impairment (MCI) patients later diagnosed as $\mathrm{AD}$ [46], and to increase the risk of developing late-onset $\mathrm{AD}$ [47]. Overexpression of TGF $\beta$ in the transgenic mouse models also reduces $A \beta$ generation and plaque burden [48]. Thus, increased TGF $\beta$ levels in both the CM and lysates by BCNU are consistent with these data. The mechanism by which $B C N U$ reduces $A \beta$ and plaque burden might be mainly through its effect on intracellular trafficking and maturation of APP. Also, unlike other oncology drugs, BCNU reduced the number of microglia, ruling out the possibility that microglia are responsible for clearing amyloid plaques. One limitation of our study is that we did not co-stain microglia with an anti-A $\beta$ antibody to stain amyloid plaques. The reduced number of microglia may be related to the decreased amyloid load. Since we did not co-stain, we cannot conclude that decreased microglia correlate with decreased plaque burden. Another limitation of our study is that we did not study the effect of short-term drug exposure on either amyloid plaques or microglia. Thus, after short-term drug treatment microglia numbers may be increased, but we do not have data to support this idea.

In cancer patients, BCNU is administered at $200 \mathrm{mg} / \mathrm{m}^{2}$ every six weeks and since the body surface area in humans is 1.6 , the total dose administered is about $320 \mathrm{mg} /$ person 


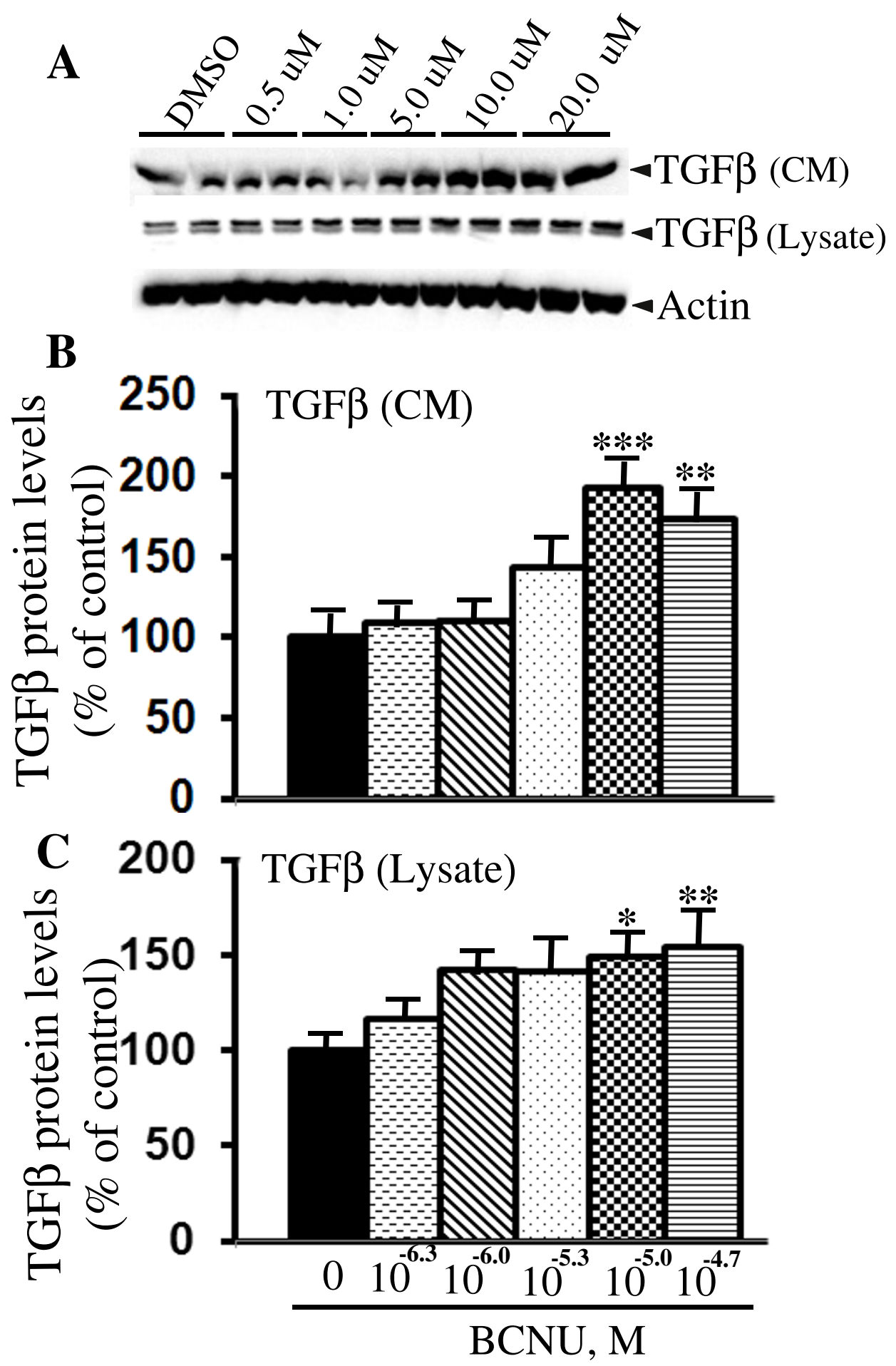

Figure 10 BCNU increases TGF $\beta$ protein levels in 7WD10 cells. A) Cells were treated with BCNU at different concentrations as indicated and, after 48 hours, the conditioned media (CM) as well as lysates were immunoblotted to detect TGF $\beta$ protein. B) ImageJ quantitation revealed significantly increased TGF $\beta$ protein levels at $10.0 \mu \mathrm{M}(73 \%, P<0.01)$ and $20.0 \mu \mathrm{M}(92 \%, P<0.001)$ in the CM. Similarly in the lysates TGF $\beta$ levels were increased at the same concentrations of $10.0 \mu \mathrm{M}(149 \%, P<0.05)$ and $20.0 \mu \mathrm{M}(154 \%, P<0.01)$. For all samples, $\mathrm{n}=4 \pm \mathrm{SEM}$. ${ }^{*}, P<0.05$, ${ }^{* *}, P<0.01,{ }^{* * *}, P<0.001$ versus untreated controls by analysis of variance (ANOVA) followed by post-hoc test by Dunnett multiple comparisons. $\mathrm{BCNU}, 1,3$ bis (2-chloroethyl)-1-nitrosourea; SEM, standard error of the mean; TGF $\beta$, transforming growth factor $\beta$. 
(or approximately $4 \mathrm{mg} / \mathrm{kg}$ body weight), an equivalent of $300 \mu \mathrm{M}$ in an adult. The major limiting factor of BCNU is its toxicity, particularly hepatic and pulmonary fibrosis. Therefore, to avoid systemic toxicity, patients with solid brain tumors are implanted with $\mathrm{BCNU}$ wafers, up to eight per patient, each with $7.7 \mathrm{mg}$ of BCNU. Thus, a very high concentration of $\mathrm{BCNU}$ is released in the brain, which may be responsible for some of the adverse effects, such as the seizures and brain edema seen in patients implanted with BCNU wafers. Comparing these doses in humans and extrapolating to mice, our in vivo dose of $0.5 \mathrm{mg} / \mathrm{kg}$ body weight in mice, an equivalent of $30 \mu \mathrm{M}$ is about 10-fold less compared to the dose in humans and, so, not expected to cause any systemic or neuro-toxicity. In fact we did not notice any signs of toxicity during the entire treatment period. However, in mice significant toxicity of BCNU in terms of increased cell death has been reported when $\mathrm{BCNU}$ is administered at 20 [49] or 10 [50] $\mathrm{mg} / \mathrm{kg}$ body weight. Because the LD50 dose in mice for $\mathrm{BCNU}$ is 52 (males) and 46 (females) $\mathrm{mg} / \mathrm{kg}$ body weight [51], respectively, our dose of $0.5 \mathrm{mg} / \mathrm{kg}$ is about 100 times lower than the LD50 dose in mice or 20 to 40 times lower than the doses used by other studies where significant toxicity was encountered. Taken together our data clearly suggest that BCNU reduces the levels of $A \beta 40$ as determined using $A \beta$-specific antibodies and amyloid plaque burden determined by thioflavin $\mathrm{S}$ staining at nontoxic concentrations. Thus, this is definitive and confirmatory evidence that $\mathrm{BCNU}$ treatment reduces amyloidogenic processing of APP in vivo.

The most interesting observation made in the present study is that BCNU reduced amyloidogenic processing of APP independent of secretases. Thus, the plethora of side effects resulting from inhibition of secretases which is the predominant reason for their failures in clinics can be completely avoided $[52,53]$. The recent discovery of a coding mutation on the APP gene (A673T) which provides significant protection against cognitive decline in both $\mathrm{AD}$ patients as well as normal elderly individuals [54] is strong proof of the principle evidence that reducing $A \beta$ levels is an effective therapeutic approach for AD. Therefore, discovery of any anti-A $\beta$ drug, especially those which modulate $A \beta$ generation independent of secretases would have wider clinical applications. Our finding that BCNU has a potent anti-A $\beta$ effect is in line with the anecdotal clinical observations that AD and cancer are inversely related. Although there is no epidemiological evidence linking decreased risk of developing AD after chemotherapy, our data suggest that cancer drugs, such as BCNU, can be effective therapeutic agents against AD.

\section{Conclusions}

In summary, our data have revealed for the first time that chronic BCNU administration at a non-toxic dose leads to robust reduction of $A \beta 40$ levels and amyloid plaque burden as a consequence of decreased amyloidogenic processing of APP. Decreased amyloid plaques may possibly result from altered trafficking and processing of APP. Thus, BCNU may emerge as a novel and powerful anti-A $\beta$ drug for the effective treatment and prevention of AD. Since BCNU acts independent of secretases, all the inadvertent side effects due to their off-target effects can be completely avoided.

\section{Abbreviations}

$A \beta$ : amyloid $\beta$; ACAT: acyl-coenzyme A cholesterol acyl transferase; AD: Alzheimer's disease; APP: amyloid precursor protein; BACE: $\beta$-secretase; BBB: blood brain barrier; BCNU: 1, 3 bis (2-chloroethyl)-1-nitrosourea; BSA: bovine serum albumin; CAA: cerebral amyloid angiopathy; $\mathrm{CHO}$ cells: Chinese hamster ovary cells; CM: conditioned media; CTF: C-terminal fragment; DAPI: 4',6-diamidino-2-phenylindole; DMSO: dimethyl sulfoxide; DTP:

Developmental Therapeutics Program; EGTA: ethylene glycol tetraacetic acid; ELISA: enzyme-linked immunosorbent assay; ER: endoplasmic reticulum; FA: formic acid; IgG: immunoglobulin G; LDH: lactate dehydrogenase; LTBP-1: latent transforming growth factor-binding protein-1; MS: multiple sclerosis; MTT: 3-(4, 5-dimethylthiazol-2-yl)-2, 5-diphenyltetrazolium bromide; NP40: nonidet-P40; PBS: phosphate-buffered saline; PFA: paraformaldehyde; PKA protein kinase A; PVDF: polyvinylidene difluoride; RT: room temperature; TBI: traumatic brain injury; TBS-T: tris-buffered saline with Tween; TGF $\beta$ : transforming growth factor $\beta$.

\section{Authors' contributions}

MKL is responsible for designing the overall study and writing the manuscript. CDH and DD equally contributed to the study by performing experiments. JPP and HW also performed experiments. KAP designed and performed the analytical part of the experiments. DM designed and performed the secretase experiments. AN designed the chemistry part of the experiments. All authors have read and approved the manuscript for publication.

\section{Competing interests}

The authors declare that they have no competing interests.

\section{Acknowledgements}

We want to acknowledge the NCI/DTP Open Chemical Repository from where the oncology library set II with 89 compounds was freely obtained for initial screenings. We are also grateful for the seed money obtained in the form of an institutional grant from the Alzheimer's and Aging Institute TPIMS, Florida. This work was also supported by the James and Esther King Biomedical Research Program (2KN05 to DM).

\section{Author details}

${ }^{1}$ Section of Neurobiology, Torrey Pines Institute for Molecular Studies, SW Village Parkway 11350, Port Saint Lucie, FL 34987, USA. ²Department of Chemistry, Torrey Pines Institute for Molecular Studies, SW Village Parkway 11350, Port Saint Lucie, FL 34987, USA. ${ }^{3}$ Peptide-based Therapeutics, Torrey Pines Institute for Molecular Studies, SW Village Parkway 11350, Port Saint Lucie, FL 34987, USA.

Received: 17 August 2012 Accepted: 26 March 2013 Published: 26 March 2013

\section{References}

1. Wimo A, Winblad B, Johnson L: The worldwide societal costs of dementia: estimates for 2009. Alzheimer's Dement 2010, 6:98-103.

2. Alzheimer's Association: 2011 Alzheimer's disease facts and figures. Alzheimer's Dement 2011, 7:208-244.

3. Garber K: An end to Alzheimer's? Technol Rev 2001, 104:70-77.

4. Hardy J, Selkoe DJ: The amyloid hypothesis of Alzheimer's disease: progress and problems on the road to therapeutics. Science 2002, 297:353-356 
5. Cummings J: What can be inferred from the interruption of the semagacestat trial for treatment of Alzheimer's disease? Biol Psych 2010 68:876-878.

6. Extance A: Alzheimer's failure raises questions about disease modifying strategies. Nat Rev Drug Discov 2010, 9:749-751.

7. Swanoski MT: Homotaurine: a failed drug for Alzheimer's disease and now a nutraceutical for memory protection. Am J Health Syst Pharm 2009, 66:1950-1953.

8. Green RC, Schneider LS, Amato DA, Beelen AP, Wilcock G, Swabb EA Zavitz KH, Tarenflurbil Phase 3 Study Group: Effect of tarenflurbil on cognitive decline and activities of daily living in patients with mild Alzheimer disease: a randomized controlled trial. JAMA 2009, 302:2557-2564.

9. Blennow K, Zetterberg H, Rinne JO, Salloway S, Wei J, Black R, Grundman M, Liu E, AAB-001 201/202 Investigators: Effect of immunotherapy with bapineuzumab on cerebrospinal fluid biomarker levels in patients with mild to moderate Alzheimer's disease. Arch Neurol 2012, 69:1002-1010.

10. Nicoll JAR, Wilkinson D, Holmes C, Steart $P$, Markham H, Weller RO: Neuropathology of human Alzheimer's disease after immunization with amyloid-B-peptide: a case report. Nat Med 2003, 9:448-452.

11. Vellas B, Black R, Thal LJ, Fox NC, Daniels M, McLennan G, Tompkins C, Leibman C, Pomfret M, Grundman M, AN1792 (QS-21)-251 study team: Longterm follow-up of patients immunized with AN1792: reduced functional decline in antibody responders. Curr Alzheimer Res 2009, 6:144-151.

12. Chételat $G$, Villemagne VL, Villain N, Jones $G$, Ellis KA, Ames $D$, Martins $R N$, Masters CL, Rowe CC, AlBL Research Group: Accelerated cortical atrophy in cognitively normal elderly with high $\beta$-amyloid deposition. Neurology 2012, 78:477-484

13. Becker JA, Hedden T, Carmasin J, Maye J, Rentz DM, Putcha D, Fischl B, Greve DN, Marshall GA, Salloway S, Marks D, Buckner RL, Sperling RA, Johnson KA: Amyloid- $\beta$ associated cortical thinning in clinically normal elderly. Ann Neurol 2011, 69:1032-1042.

14. ClinicalTrials.gov. [http://clinicaltrials.gov/ct2/results?term=Alzheimer\%27s], accessed August 2012

15. Townsend M: When will Alzheimer's disease be cured? A pharmaceutical perspective. J Alzheimer's Dis 2011, 24:43-52.

16. Haapasalo A, Kovacs DM: The many substrates of presenilin/ $/$-secretase. J Alzheimer's Dis 2011, 25:3-28.

17. Citron M: Beta-secretase inhibition for the treatment of Alzheimer's disease-promise and challenge. Trends Pharmacol Sci 2004, 25:92-97.

18. Cole SL, Vassar R: The Alzheimer's disease $\beta$-secretase enzyme, BACE1. Mol Neurodeg 2007, 2:22-47.

19. Luo X, Yan R: Inhibition of BACE1 for therapeutic use in Alzheimer's disease. Int J Clin Exp Pathol 2010, 3:618-628.

20. Albert JS: Progress in the development of beta-secretase inhibitors for Alzheimer's disease. Prog Med Chem 2009, 48:133-148.

21. Johnson VE, Stewart $W$, Smith DH: Traumatic brain injury and amyloid- $\beta$ pathology: a link to Alzheimer's disease? Nat Rev Neurosci 2010, 11:361-370.

22. Smith EE, Greenberg SM: Beta-amyloid, blood vessels, and brain function. Stroke 2009, 40:2601-2606.

23. Guo L, Salt TE, Luong V, Wood N, Cheung W, Maass A, Ferrari G, RussoMarie F, Sillito AM, Cheetham ME, Moss SE, Fitzke FW, Cordeiro MF: Targeting amyloid-beta in glaucoma treatment. Proc Natl Acad Sci USA 2007, 104:13444-13449

24. Mattson N, Zetterberg H, Bianconi S, Yanjanin NM, Fu R, Mansson JE, Porter FD, Blennow K: Gamma-secretase-dependent amyloid-beta is increased in Niemann-Pick type C: a cross sectional study. Neurology 2011, 76:366-372.

25. Roe CM, Fitzpatrick AL, Xiong C, Sieh W, Kuller L, Miller JP, Williams MM, Kopan R, Behrens MI, Morris JC: Cancer linked to Alzheimer's disease. Neurology 2010, 74:106-112

26. Roe CM, Behrens Ml, Xiong C, Miller JP, Morris JC: Alzheimer's disease and cancer. Neurology 2005, 64:895-898.

27. Development Therapeutics Program. NCI/NIH. [http://dtp.cancer.gov], accessed August 2012

28. Lakshmana MK, Yoon IS, Chen E, Park SA, Bianchi E, Koo EH, Kang DE: Novel role of RanBP9 in BACE1 processing of APP and amyloid beta peptide generation. J Biol Chem 2009, 284:1863-1872.

29. Lakshmana MK, Chung JY, Wickramarachchi S, Tak E, Bianchi E, Koo EH, Kang DE: A fragment of the scaffolding protein RanBP9 is increased in
Alzheimer's disease brains and strongly potentiates amyloid beta peptide generation. FASEB J 2009, 24:119-127.

30. Driver JA, Beiser A, Au R, Kreger BE, Splansky GL, Kurth T, Kiel DP, Lu KP, Seshadri S, Wolf PA: Inverse association between cancer and Alzheimer's disease: results from the Framingham heart study. BMJ 2012, 344:1-12.

31. Koo EH, Squazzo SL: Evidence that production and release of amyloidbeta protein involves the endocytic pathway. J Biol Chem 1994 269:17386-17389

32. Perez RG, Soriano S, Hayes JD, Ostaszewski B, Xia W, Selkoe DJ, Chen X Stokin GB, Koo EH: Mutagenesis identifies new signals for beta-amyloid precursor protein endocytosis, turnover, and the generation of secreted fragments, including Abeta42. J Biol Chem 1999, 274:18851-18856.

33. Weincke JK, Wiemels J: Genotoxicity of 1, 3-bis (2-chloroethyl)-1nitrosourea (BCNU). Mutat Res 1995, 339:91-119.

34. Yesid A, Swords R, Kelly KR, Giles FJ: Clinical activity of laromustine (Onrigin) in hematologic malignancies. Expert Rev Hematol 2009, 2:481-498

35. Norman SA, Rhodes SN, Treasurywala S, Hoelzinger DB, Shapiro JR, Scheck AC: Identification of transforming growth factor-b1-binding protein overexpression in BCNU-resistant glioma cells by mRNA differential display. Cancer 2000, 89:850-861

36. Netzer WJ, Dou F, Cai D, Veach D, Jean S, Li Y, Bornmann WG, Clarkson B, $\mathrm{Xu} \mathrm{H}$, Greengard P: Gleevec inhibits beta-amyloid production but not Notch cleavage. Proc Natl Acad Sci USA 2003, 100:12444-12449.

37. He G, Luo W, Li P, Remmers C, Netzer WJ, Hendrick J, Bettayeb K, Flajolet M, Gorelick F, Wennogle LP, Greengard P: Gamma-secretase activating protein is a therapeutic target for Alzheimer's disease. Nature 2010, 467:95-98

38. Bartosek I, Russo RG, Cattaneo MT: Pharmacokinetics of nitrosoureas: levels of 1,3- bis-(2-chloroethyl)-1-nitrosourea (BCNU) in organs of normal and walker 256/B carcinoma bearing rats after i.v. bolus. Tumori 1984, 70:491-498.

39. Senior K: Gleevec does not cross blood-brain barrier. Lancet Oncol 2003, 4:198

40. Cramer PE, Cirrito JR, Wesson DW, Lee CY, Karlo JC, Zinn AE, Casali BT, Restivo JL, Goebel WD, James MJ, Brunden KR, Wilson DA, Landreth GE: ApoE-directed therapeutics rapidly clear $\beta$-amyloid and reverse deficits in $A D$ mouse models. Science 2012, 335:1503-1506.

41. Su Y, Ryder J, Ni B: Inhibition of Abeta production and APP maturation by a specific PKA inhibitor. FEBS Lett 2003, 546:407-410.

42. Huttunen HJ, Peach C, Bhattacharya R, Barren C, Pettingell W, Hutter-Paier B, Windisch M, Berezowska O, Kovacs DM: Inhibition of acyl-coenzyme A: cholesterol acyl transferase modulates amyloid precursor protein trafficking in the early secretory pathway. FASEB J 2009, 23:3819-3828.

43. Lee J, Kim CH, Kim DG, Ahn YS: Zinc inhibits amyloid beta production from Alzheimer's amyloid precursor protein in SH-SY5Y cells. Korean J Physiol Pharmacol 2009, 13:195-200.

44. Tomita S, Kirino Y, Suzuki T: Cleavage of Alzheimer's amyloid precursor protein by secretases occurs after O-glycosylation of APP in the protein secretory pathway. Identification of intracellular compartments in which APP cleavage occurs without using toxic agents that interfere with protein metabolism. J Biol Chem 1998, 273:6277-6284.

45. Chapuis J, Vingtdeux V, Campagne F, Davies P, Marambaud P: Growth arrest-specific 1 binds to and controls the maturation and processing of the amyloid-beta precursor protein. Human Mol Genet 2011, 20:2026-2036.

46. Scarpini $E$, Annoni $G$, Vergani $C:+10 \mathrm{~T} / \mathrm{C}$ polymorphisms in the gene of transforming growth factor beta1 are associated with neurodegeneration and its clinical evolution. Mech Ageing Dev 2007, 128:553-557

47. Caraci F, Bosco P, Signorelli M, Spada RS, Cosentino FI, Toscano G: The CC genotype of transforming growth factor- $\beta$ increases the risk of lateonset Alzheimer's disease and is associated with AD-related depression. Eur Neuropsychopharmacol 2012, 22:281-289.

48. Wyss-Corey T, Lin C, Yan F, Yu G-Q, Rohde M, McConlogue L, Masliah E, Mucke L: TGF- $\beta 1$ promotes microglial amyloid- $\beta$ clearance and reduces plaque burden in transgenic mice. Nature Med 2001, 7:612-618.

49. Helal GK, Aleisa AM, Helal OK, Al-Rejaie SS, Al-Yahya AA, Al-Majed AA, AlShabanah OA: Metallothionein induction reduces caspase-3 activity and TNFalpha levels with preservation of cognitive function and intact hippocampal neurons in BCNU-treated rats. Oxid Med Cell Longev 2009, 2:26-35 
50. Dietrich J, Han R, Yang Y, Mayer-Proschel M, Noble M: CNS progenitor cells and oligodendrocytes are targets of chemotherapeutic agents in vitro and in vivo. J Biol 2006, 5:22-29.

51. Kehrer JP, Paraidathathu T: Enhanced oxygen toxicity following treatment with 1,3- bis(2-chloroethyl)-1-nitrosourea. Fundam Appl Toxicol 1984, 4:760-767.

52. Extance A: Alzheimer's failure raises questions about disease modifying strategies. Nat Rev Drug Discov 2010, 9:749-751.

53. May PC, Dean RA, Lowe SL, Martenyi F, Sheehan SM, Boggs LN: Robust central reduction of amyloid- $\beta$ in humans with an orally available, nonpeptidic $\beta$-secretase inhibitor. J Neurosci 2011, 31:16507-16516.

54. Jonsson T, Atwal JK, Steinberg S, Snaedel J, Jonsson PV, Bjornsson S: A mutation in APP protects against Alzheimer's disease and age-related cognitive decline. Nature 2012, 488:96-99.

Pre-publication history

The pre-publication history for this paper can be accessed here: http://www.biomedcentral.com/1741-7015/11/81/prepub

doi:10.1186/1741-7015-11-81

Cite this article as: Hayes et al: Striking reduction of amyloid plaque burden in an Alzheimer's mouse model after chronic administration of carmustine. BMC Medicine 2013 11:81.

\section{Submit your next manuscript to BioMed Central} and take full advantage of:

- Convenient online submission

- Thorough peer review

- No space constraints or color figure charges

- Immediate publication on acceptance

- Inclusion in PubMed, CAS, Scopus and Google Scholar

- Research which is freely available for redistribution

Submit your manuscript at www.biomedcentral.com/submit 